UNIVERSIDADE DE SÃO PAULO

FACULDADE DE ODONTOLOGIA

\title{
SUBSÍDIOS PARA O PLANEJAMENTO DE CUIDADOS ESPECIAIS PARA O ATENDIMENTO ODONTOLÓGICO DE PACIENTES PORTADORES DE DIABETES MELLITUS TIPO 2
}

\section{LUÍS ANTONIO CHERUBINI CARVALHO}

Dissertação apresentada à Faculdade de Odontologia da Universidade de São Paulo, para obter o Título de Mestre, pelo Programa de Pós-Graduação em Odontologia. Área de Concentração: Deontologia e Odontologia Legal.

São Paulo 2002 
UNIVERSIDADE DE SÃO PAULO

FACULDADE DE ODONTOLOGIA

\section{SUBSÍDIOS PARA O PLANEJAMENTO DE CUIDADOS ESPECIAIS PARA O ATENDIMENTO ODONTOLÓGICO DE PACIENTES PORTADORES DE DIABETES MELLITUS TIPO 2}

LUÍS ANTONIO CHERUBINI CARVALHO

Dissertação apresentada à Faculdade de Odontologia da Universidade de São Paulo, para obter o Título de Mestre, pelo Programa de Pós-Graduação em Odontologia. Área de Concentração: Deontologia e Odontologia Legal.

Orientador:

Prof. Dr. José Leopoldo Ferreira Antunes

São Paulo

2002 
Data da Defesa: 05/02/2003

\section{Banca Examinadora}

Prof. Dr. José Leopoldo Ferreira Antunes

Julgamento: Aprovado Assinatura:

Profa. Dra. Hilda Ferreira Cardoso

Julgamento: Aprovado Assinatura:

Prof. Dr. Carlos Botazzo

Julgamento: Aprovado Assinatura: 
Não me impeça de vero que anseio,

Que a morte de tudo que acredito não me tape os ouvidose a boca;

Por que metade de mim é o que eu grito...

mas a outra metade é silêncio...

Que a música que ouço ao longe seja linda a inda que tristeza;

Que a mulher que eu amo seja para sempre amada, mesmo que distante;

Porque metade de mim é partida... e a outra metade é saudade...

Que as palavras que eu falo não sejam ouvidas como

prece e nem repetidascom fervor, apenas respeitadas...

como a única coisa que resta a um homem inundado de sentimento;

Porque metade de mim é o que ouço...

mas a outra metade é o que calo...

Que essa minha vontade de ir embora se transforme na calma e na pazque eu mereço;

Que essa tensão que me corrói por dentro seja um dia recompensada;

Porque metade de mim é o que penso... e a outra metade um vulcão...

Que o medo da solidão se afaste...

que conviva comigo mesmo

e que se tome ao menos suportável;

Que o espelho reflita em meu rosto um doce somiso

que me lembro ter dado na infância;

Por que metade de mim é a lembrança do que fui...

e a outra metade... não sei...

Que me seja preciso ma is que uma simples alegria

para me fazer aquietar o espíito;

E que teu silêncio me fale cada vez mais;

Porque metade de mim é abrigo...

mas a outra metade é cansaço...

Que a arte nos aponte uma resposta,

mesmo que ela não saiba;

Eque ninguém a tente complicar, porque é preciso

simplicidade para faze-la florescer;

Porque metade de mim é a platéia...

e a outra metade é canção...

E que minha loucura seja perdoada...

Por que metade de mim é AMOR... e a outra metade...TAMBÉM... 

$\mathcal{A}$ De us, por tudo e acima de tudo;

em quem acredito.

Frente às adversidades e à simplicidade de cada dia, nada era mais importante do que a boa formação e educação de seus filhos, alicerçada no respeito e na ajuda a todos aqueles a que pudessem alc ançar.

Desta forma cresci, e conservo essa filosofia de vida.

Obrigado aos meus pais Ioaquim e Rosa, por esta lição, e por tudo aquilo que proporcionaram e continuam me proporcionando; desse infinito poço de sabedoria chamado amor.

À Rosana, minha irmã, que sempre de maneira afe tuosa esteve comigo nos momentos em que um sorriso era mais importante que as palavras. 
AGRADECI MENTOS 
Ao Prof. Dr. José Leopoldo Ferreira Antunes - exemplo de dignidade, segurança e conhecimento, o que o torna um excelente orientador. Obrigado pela oportunidade, confiança, amizade e respeito. Admiro-o como profissional e como pessoa.

À Profa. Dra. Hilda Ferreira Cardozo, com quem aprendi a conviver com respeito e admiração. Pela profissional que é, no sentido amplo que representa essa palavra. Muitas vezes, foi você fonte de calmaria nos momentos mais difíceis. Obrigado pelas palavras sempre oportunas e, além de tudo por ser, hoje, minha grande amiga

Ao Prof. Dr. Carlos Botazzo, pelo apoio e por compartilhar comigo às filosofias da clínica odontológica. Minha admiração e carinho.

À Luciana Maria Cavalcante Melo, pela sua companhia nesse tempo em que nos conhecemos, convivemos e juntos passamos por alegrias e tristezas. Mas sem dúvida, mesmo os momentos tristes foram menos "pesados" com você ao meu lado. Obrigado pelo apoio e amor. 
Aos Profs. do Departamento de Odontologia Social da FOUSP; Dalton, Edgar, Ida, Maria Ercilia, Moacyr, Rodolfo, Rogério, Simone e Toninho que, mais do que transmitir conhecimento, transmitem amizade e apoio.

À Profa. Elaine Alves; as palavras são insuficientes para demonstrar meu carinho e admiração. Sua presença é imprescindível para a formação de novos profissionais, pois os torna mais humanos.

Ao amigo Walmyr Ribeiro de Mello, que me auxiliou na coleta de dados, e por ter aberto as portas de seu consultório.

À Ana Miriam Gebara Carboni, pelo auxílio na coleta de dados.

À Prof. Dra. Karen López Ortega, amiga, orientadora e exemplo a ser seguido.

À Profa. Dra. Marina Helena C. G. Magalhães, por me dar uma oportunidade no Centro de Atendimento de Pacientes Especiais (CAPEFOUSP), e por todo o apoio em meu trabalho.

Às funcionárias do CAPE, Sandra, Gilmara, Divina, Maria Helena, Isabel, Maria José, pela ajuda, e por serem responsáveis pelo tratamento especial aos pacientes daquele Centro de Atendimento.

Aos amigos da pós-graduação; Tatiana, Márcio, Aiko, Cecília, Cilene, Evelyn, Fábio, Fernando, José Reynaldo, Julie, Leonardo, Luciana, Luis Fernando, Mutsumi, Nilcéa, Plínio, Regina, Rodrigo, Sara, Solange, Ulisses e Vitor, por tudo que passamos juntos nestes dois anos.

Às funcionárias do Departamento, Andréia dos Santos Teixeira e Sônia Castro Lucia Lopes, obrigado pela constante ajuda, amizade e gentileza.

À secretária do Curso de Pós-Graduação em Deontologia e Odontologia Legal, Marieta Trancoso de Castro, pelo apoio, amizade e carinho.

À bibliotecária Luzia Marilda Zoppei Murgia Moraes pelo apoio, ajuda e amizade. E a os funcionários do Serviço de Documentação Odontológica da FOUSP, que a todos atendem com dedicação e competência.

À Cidinha, da biblioteca, que me auxiliou na formatação da dissertação.

À Regina, secretária do Departamento de Prótese, que me ajudou nos momentos finais do meu trabalho 
“Nunca sabemos se nos arrumamos a contento quando nos pomos à rua e, francamente, não sei se este texto conseguirá cobrir convenientemente minha nudez." 


\section{SUMÁRIO}

p.

LISTA DE FIGURAS

LISTA DE TABELAS

LISTA DE ABREVIATURAS E SIGLAS

LISTA DE SÍMBOLOS

RESUMO

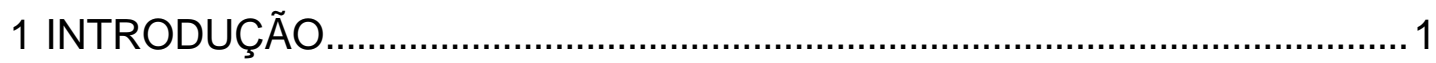

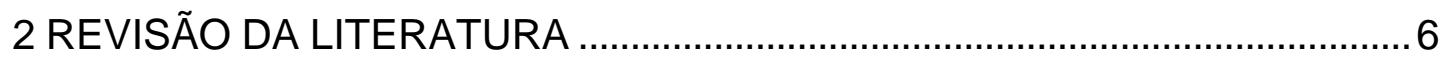

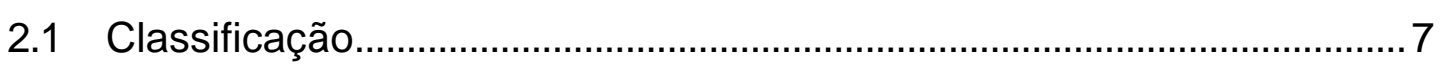

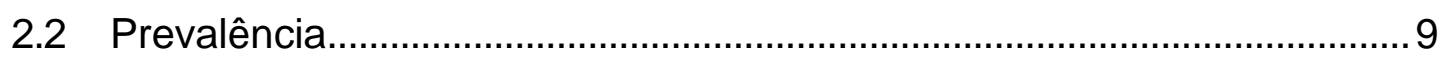

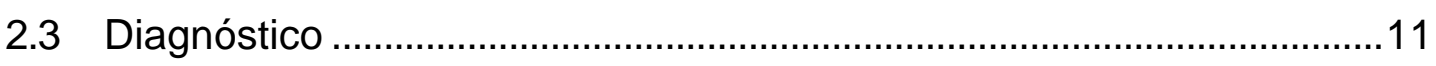

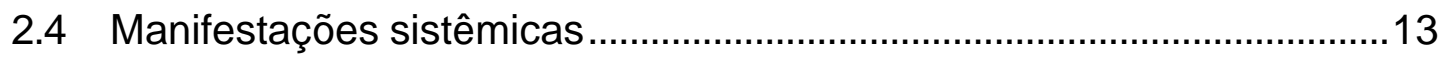

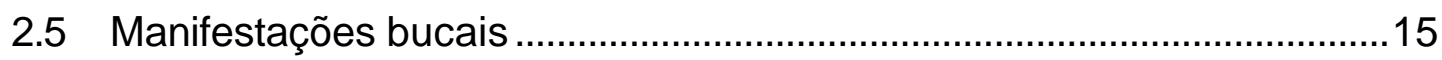

2.6 Conduta clínica ................................................................................. 17

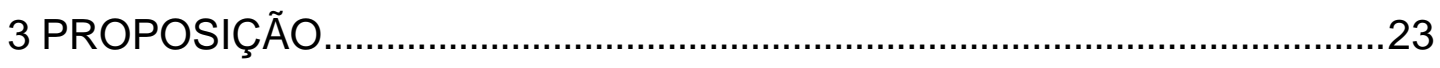

4 MATERIAL E MÉTODOS .........................................................................24

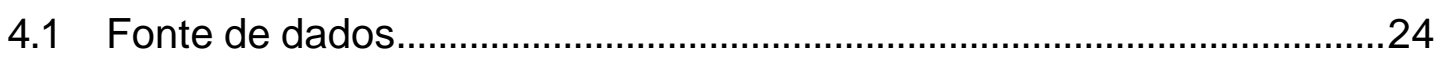

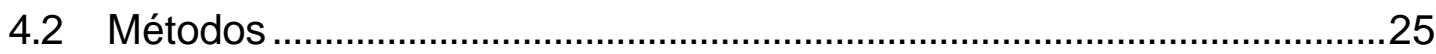




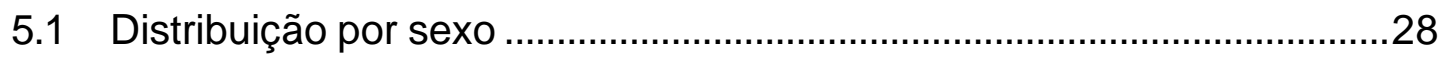

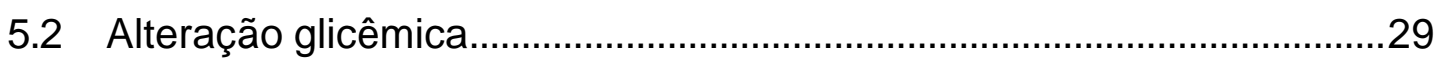

5.3 Antecedentes familiares com diabetes .................................................29

5.4 Uso de medicação para o controle do diabetes.........................................30

5.5 Acompanhamento médico .......................................................................

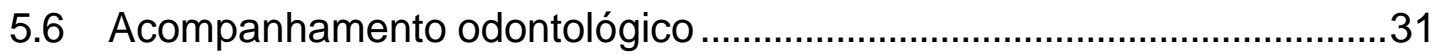

5.7 Informação do participante ao cirurgião dentista ……………………........32

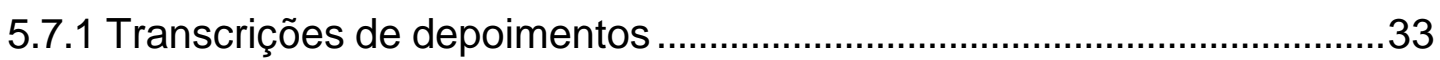

5.8 Informação do cirurgião dentista aos pacientes sobre a importância do

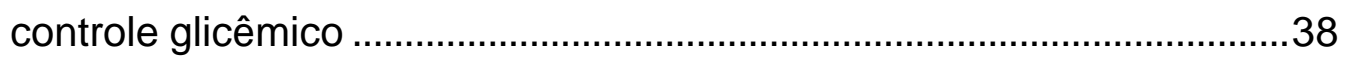

5.9 Manifestações sistêmicas auto-referidas …………………………….......39

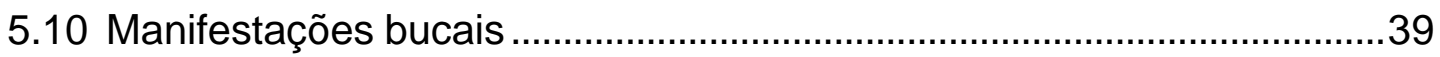

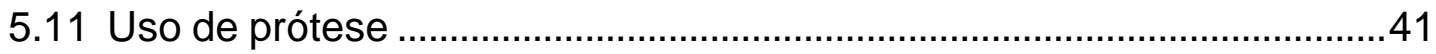

5.12 Auto-percepção das condições de saúde bucal.......................................42

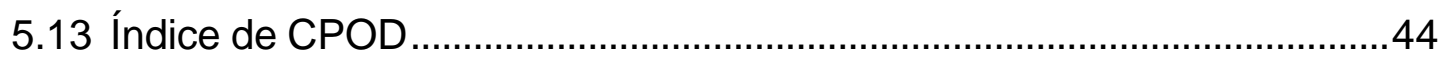

6 DISCUSSÃO

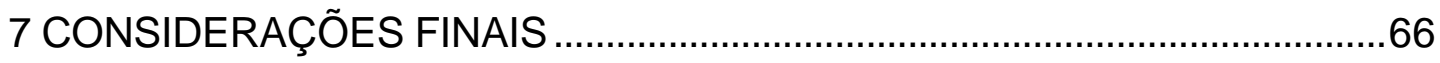

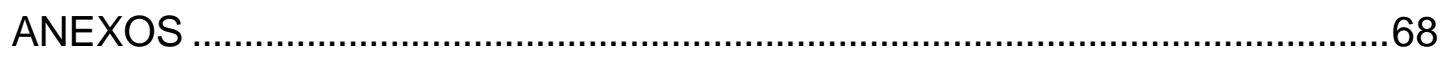

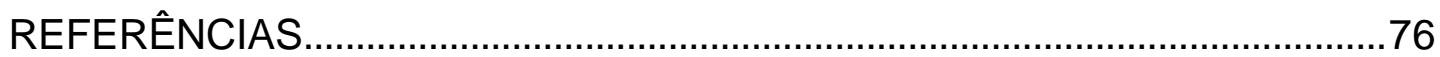

SUMMARY 


\section{LISTA DE FIGURAS}

Gráfico 5.1 - Alteração da glicemia por sexo e faixa etária ............................29

Gráfico 5.2 - Percepção das condições de saúde bucal (pelo paciente).......43

Gráfico 5.3 - Índice de CPOD dos participantes da pesquisa .45 


\section{LISTA DE TABELAS E QUADROS}

Tabela 5.1 - Distribuição do sexo por faixa etária

Tabela 5.2 - Participantes com antecedentes familiares com diabetes e os que faziam uso de medicação para controle (valores absolutos e porcentagem) .30

Tabela 5.3 - Participantes em acompanhamento médico e sua distribuição nos serviços

Tabela 5.4 - Participantes em acompanhamento odontológico e sua distribuição nos serviços. .32

Tabela 5.5 - Informação ao cirurgião dentista sobre ser portador de diabetes .33

Tabela 5.6 - Informação do cirurgião dentista sobre a importância da boa condição de saúde bucal no controle da glicemia. .38

Tabela 5.7 - Manifestações sistêmicas auto-referidas pelos participantes da pesquisa 39

Tabela 5.8 - Manifestações bucais encontradas nos participantes da pesquisa .40 
Tabela 5.9 - Alteração do fluxo salivar.

Tabela 5.10 - Distribuição dos participantes de acordo com o tipo de próteses utilizada .42

Tabela 5.11 - Prevalência da auto-avaliação-negativa nos participantes apresentando diferentes sintomas bucais .44

Quadro 2.1 - Classificação do Diabetes Mellitus. 8

Quadro 2.2 - Valores da glicose plasmática $(\mathrm{em} \mathrm{mg} / \mathrm{dll})$ para diagnóstico de Diabetes Mellitus e seus estágios pré-clínicos .13

Quadro 2.3 - Anamnese direcionada para o Diabetes Mellitus, segundo Gregori 20 


\section{LISTA DE ABREVIATURAS E SIGLAS}

\begin{tabular}{|c|c|}
\hline a.C. & Antes de Cristo \\
\hline ANAD & Associação Nacional de Assistência ao Diabético \\
\hline CAPE-FOUSP & $\begin{array}{l}\text { Centro de Atendimento a Pacientes Especiais da } \\
\text { Faculdade de Odontologia da Universidade de São } \\
\text { Paulo }\end{array}$ \\
\hline CBD & Consenso Brasileiro de Diabetes \\
\hline CPOD & Índice de dentes cariados perdidos e obturados \\
\hline $\mathrm{DM}$ & Diabetes Mellitus \\
\hline $\mathrm{F}$ & Feminino \\
\hline g & Gramas \\
\hline GGT Oral & Teste de tolerância à glicose oral \\
\hline $\mathrm{h}$ & Horas \\
\hline IDDM & Diabetes Mellitus insulino-dependente \\
\hline $\mathrm{Kg}$ & Quilograma \\
\hline M & Masculino \\
\hline $\mathrm{mg} / \mathrm{dl}$ & Miligramas por decilitro \\
\hline $\mathrm{mmHg}$ & Milímetros de mercúrio \\
\hline NIDDM & Diabetes Mellitus não-insulino-dependente \\
\hline OMS & Organização Mundial de Saúde \\
\hline
\end{tabular}




$\begin{array}{ll}\text { PPRI } & \text { Prótese parcial removível inferior } \\ \text { PPRS } & \text { Prótese parcial removível superior } \\ \text { PTI } & \text { Prótese total inferior } \\ \text { PTS } & \text { Prótese total superior } \\ \text { SPS } & \text { Secretária de Políticas da Saúde } \\ \text { SUS } & \text { Sistema Único de Saúde } \\ \text { T } & \text { Total } \\ \text { WHO } & \text { World Health Organization }\end{array}$




\section{LISTA DE SÍMBOLOS}

$\begin{array}{ll}\mathrm{n}^{\circ} & \text { Número absoluto } \\ \% & \text { Porcentagem } \\ > & \text { Maior que } \\ < & \text { Menor que }\end{array}$

Maior ou igual a

Menor ou igual a 


\section{RESUMO}

\section{SUBSÍDIOS PARA O PLANEJAMENTO DE CUIDADOS ESPECIAIS PARA O ATENDIMENTO ODONTOLÓGICO DE PACIENTES PORTADORES DE DIABETES MELLITUS TIPO 2}

Além das manifestações sistêmicas que acometem os pacientes portadores de Diabetes Mellitus (DM), como angiopatias, cardiopatias, retinopatias, nefropatias e hipertensão arterial, estes pacientes apresentam também respostas diminuídas a infecção, quando descompensados, fazendo que o transcurso da doença se desenvolva de forma diferenciada do paciente normoglicêmico. Esta característica irá se apresentar, também, na cavidade bucal, fato este que deverá alertar o cirurgião dentista quanto ao manejo adequado destes pacientes, eliminando os riscos de complicações durante e pós-tratamento. Para tanto, é necessário conhecer a prevalência das manifestações bucais que mais acometem estes indivíduos, assim como as complicações sistêmicas associadas, as quais irão intervir nesta conduta. $O$ objetivo deste trabalho foi apresentar uma população, já sabidamente, portadora de DM tipo 2, caracterizando as alterações sistêmicas e as manifestações bucais apresentadas por estes pacientes no momento em que se apresentaram para atendimento odontológico. Foram examinados 372 participantes, na 4⿳亠丷厂 Campanha gratuita de prevenção, educação e detecção em diabetes realizada pela Associação Nacional de Assistência ao 
Diabético - ANAD - no ano de 2001, com idade entre 32 a 87 anos, sendo 191 do sexo masculino e 181 do sexo feminino,. Primeiramente foi preenchido um questionário contendo informações auto-referidas sobre alterações metabólicas pré-existentes e também transcrito para a ficha o valor da glicemia e pressão arterial. Procurou-se verificar se estes participantes estavam em acompanhamento médico, odontológico e se utilizavam algum tipo de medicação para controle da glicemia. A percepção de condições de saúde bucal também foi questionada e classificada em aval positivo e negativo, com escalas. Posteriormente foi realizado exame bucal. Os resultados mostram que $46 \%$ se apresentaram com hipertensão arterial, a retinopatia e a neuropatia foi observada em $31 \%$ dos participantes, angiopatia em $20 \%$, cardiopatia em $19 \%$ e nefropatia em $10 \%$. Dos participantes, $80 \%$ realizavam acompanhamento médico e 37\% realizavam acompanhamento odontológico, sendo que $78 \%$ utilizavam medicação para o controle da glicemia. Em relação à auto-percepção das condições de saúde bucal, 38,5\% avaliavam positivamente e 37,5\% avaliavam negativamente. Quanto às manifestações bucais, os achados mais expressivos foram: exposição radicular com sensibilidade (57\%), gengivite (45\%) e diminuição de fluxo salivar (44\%). Concluímos que em função das múltiplas e freqüentes manifestações bucais apresentadas por estes pacientes, os cirurgiões dentistas devem receber formação específica para o diagnóstico e desenvolvimento desses agravos, informação esta que deverá capacitá-lo inclusive para o atendimento sob a agravante de sua condição clínica alterada. 


\section{INTRODUÇÃO}

"Em fevereiro de 2000, a Secretária de Políticas da Saúde (SPS) iniciou a elaboração do Plano Nacional de Reorganização da Atenção à Hipertensão Arterial e ao Diabetes Mellitus que, entre outras, prevê a intensificação de ações voltadas à prevenção primária - redução e controle de fatores de risco - detecção, vinculação e tratamento de portadores dessas patologias na rede básica de saúde, capacitação de recursos humanos e melhoria do atendimento especializado e da assistência farmacêutica."

Ministério da Saúde, 2001.

Descrito há mais de 3.500 anos o Diabetes Mellitus (DM) tem papel relevante como problema de saúde pública mundial, existindo 140 milhões de pessoas portadoras desta patologia; e o mais alarmante, segundo Fraige Filho (1999) em dados da Organização Mundial de Saúde (OMS), é que a projeção desse valor para 2025 é de 300 milhões.

Lalla \& D'Ambrosio (2001) relataram que nos Estados Unidos este número chega a 16 milhões de pessoas, ou seja, 6\% da população, com aproximadamente 800 mil novos casos diagnosticados a cada ano. Citaram que cerca de $20 \%$ dos adultos acima de 65 anos são portadores de DM.

Costa \& Almeida Neto (1998) alegaram que nos Estados Unidos este número dobra a cada 15 anos, sendo sua prevalência no Brasil 
aproximadamente 5 a 8 milhões de portadores, tratando-se, desta forma, de assunto de destaque na atualidade por ser considerado um dos problemas mais importantes de saúde pública.

Segundo Sonis et al. (1996), a deficiência de insulina, além de acarretar anormalidade na utilização de glicose, leva a transtornos no metabolismo de proteínas, aumentando a desintegração das gorduras ocasionando, consequentemente, elevação na formação de cetonas. Com deficiência grave de insulina, pode haver acúmulo de corpos cetônicos, resultando em cetoacidose. Como característica clínica, estes pacientes se apresentam letárgicos, desidratados e confusos, com respiração exagerada e hálito tendo odor de frutas (hálito cetônico). A alteração do estado mental e instabilidade cardiovascular resulta da cetoacidose grave, podendo levar ao coma ou morte se medidas terapêuticas não forem instituídas prontamente. Somadas as complicações metabólicas, estes pacientes podem desenvolver complicações vasculares, neurológicas e infecciosas. Indivíduos portadores de diabetes possuem elevada ocorrência de doenças nos grandes e pequenos vasos (angiopatias). Nas macroangiopatias, as complicações se manifestam por doença coronária acelerada, doença cerebrovascular e doença vascular periférica. As microangiopatias pode causar retinopatia diabética, que pode levar a cegueira, e também doença renal diabética, podendo ocasionara insuficiência renal. Estes pacientes são propensos a infecção, devido ao comprometimento das respostas do hospedeiro.

A OMS aponta que esses fatores são responsáveis por gastos expressivos em saúde, além de substancial redução da capacidade de 
trabalho e da expectativa de vida (Childhood diabetes, epidemics and epidemiology, 1992).

Vários trabalhos têm abordado as manifestações bucais associadas à descompensação glicêmica destes pacientes (Magalhães et al., 1999; Cherubini et al., 2000).

Shlossman et al. (1990) realizando estudo nos índios Pima, que têm a maior taxa de prevalência de diabetes tipo 2 no mundo, citou a forte correlação entre a prevalência da periodontite e do diabetes tipo 2; indicou ainda que os indivíduos portadores de diabetes têm uma maior perda de elementos dentários, quando comparados com indivíduos que não apresentam a doença.

Nelson et al. (1990) apontaram que 59,6\% dos índios Pima com diabetes tipo 2 têm problemas periodontais, alegando ainda que, particularmente, em indivíduos com pobre controle metabólico ou descompensados, esta patologia é claramente um fator de risco para a doença periodontal.

Várias outras alterações bucais têm sido observadas em pacientes diabéticos. lacopino (1995) caracterizou as alterações da microflora oral desses pacientes, como um dos fatores responsáveis por doenças oportunistas como herpes e candidíase. Estudos recentes têm identificado o aumento da freqüência destas manifestações, principalmente quando os pacientes estão descompensados em sua taxa de glicemia sanguínea (Novaes Jr. et al., 1991a,b; Karjalainen et al., 1994). 
O hálito cetônico, como cita alguns autores, associado à degradação de gordura para a produção de energia; xerostomia e redução parcial do fluxo salivar; atrofia de papila lingual; sensibilidade, ardência e dor na mucosa oral; aumento da incidência de cáries; dificuldade na adaptação de próteses dentárias; e hipertrofia de glândulas salivares maiores como outras manifestações bucais de interesse (Zachariasen, 1992; Galili et al., 1994; Carboni \& Fraige Filho, 1998).

Quanto à conduta odontológica nos pacientes portadores de diabetes, Barcellos et al. (2000) relataram que não se deve empregar anestésicos locais que contenham vasoconstritor à base de adrenalina, devido ao fato do hormônio provocar quebra de glicogênio em glicose, podendo ocasionar hiperglicemia. Aponta também para atenção quanto ao uso do anestésico com vasoconstritor do tipo epinefrina, visto que estes pacientes estão, freqüentemente, sujeitos à isquemia por causa da microangiopatia. Sugere a utilização de vasoconstritores sintéticos e alerta que $2 / 3$ dos pacientes portador de diabetes têm também hipertensão arterial associada, o que contra-indica o uso de vasoconstritor, propondo que em todos os casos de diabetes diagnosticados, o dentista deve consultar o médico do paciente antes de administrar qualquer anestésico. Destaca também, que os desequilíbrios metabólicos devem ser evitados durante o período de tratamento dentário, para isso, os pacientes devem ser instruídos sobre a realização da dieta adequada e o uso dos medicamentos, reduzindo os problemas relacionados a hiperglicemia e hipoglicemia. O profissional deve procurar diminuir a tensão e o risco de infecção. 
Quanto a avaliação do paciente portador de diabetes, alguns autores

afirmam que alguns itens devem ser observados durante a anamnese, como: tipo de diabetes, qual o tratamento realizado, o grau de controle metabólico e a presença de complicações associadas (Gregori, 1974; Diabetes and periodontal diseases, 1996; Sonis et al., 1996).

Devido a todos transtornos que o diabetes provoca, a responsabilidade do cirurgião dentista dentro de uma equipe interdisciplinar torna-se cada vez maior, visto a responsabilidade de debelar os focos de infecção de origem bucal que contribuem na descompensação e evitando condutas que possam comprometer o estado geral de saúde do paciente. Para tal, é de extrema importância que se estabeleça o planejamento dos cuidados especiais para 0 atendimento odontológico dos pacientes diabéticos, diminuindo os riscos de intercorrências durante e após o atendimento. 


\section{REVISÃO DA LITERATURA}

Os sintomas clínicos do Diabetes Mellitus são conhecidos desde a antigüidade. Setian et al. (1995) citaram em seu trabalho que os primeiros dados sobre a doença datam de 1.000 a.C. vindo do Egito, e que na Índia, por volta de 400 a.C., CharaK e Susrut a caracterizaram através do caráter adocicado da urina, diferenciando-a ainda em dois tipos: do obeso e do paciente que, no início da doença, apresentava emagrecimento e desidratação, além de polidipsia e poliúria. Citaram, também, que Celsus, há cerca de 2.000 anos, foi quem nomeou a doença de "Diabetes", que significa sifão, e "Mellitus" que vem do grego meli; significa mel.

Atualmente conceitua-se o DM como uma síndrome de etiologia múltipla, decorrente da falta de insulina e/ou da incapacidade da mesma de exercer adequadamente seus efeitos. Caracteriza-se por hiperglicemia crônica, com distúrbio do metabolismo dos carboidratos, lipídios e proteínas (Definition, diagnosis and classification of diabetes mellitus and its complications, 2002).

Esta produção diminuída ou alterada de insulina pelo pâncreas e as conseqüentes modificações no metabolismo de proteínas, gorduras, sais 
minerais e principalmente da glicose irá se associar a múltiplas manifestações clínicas.

\subsection{Classificação}

O DM é classificado em dois tipos principais: o tipo 1, associado à absoluta deficiência de insulina pancreática, e o tipo 2 - deficiência parcial de insulina, que afeta principalmente indivíduos obesos; uma vez que a obesidade confere resistência à ação periférica da insulina (Gross et al., 2002; Costa e Almeida Neto, 1998). A nova classificação, atualmente recomendada segundo o Consenso Brasileiro de Diabetes (CBD) (2000) e apresentada no Quadro 2.1, baseia-se na etiologia do DM, eliminando os termos "diabetes mellitus insulino-dependente" (IDDM) e "não-insulinodependente" (NIDDM). O CBD (2000, p.6) esclarece também que:

- "O DM tipo 1 resulta primeiramente da destruição das células beta do pâncreas e tem tendência a cetoacidose. Inclui casos decorrentes de doença auto-imune e aqueles nos quais a causa da destruição das células beta não é conhecida;

- "O DM tipo 2 resulta, em geral, de graus variáveis de resistência à insulina e deficiência relativa de secreção de insulina. A maioria dos pacientes tem excesso de peso e a 
cetoacidose ocorre apenas em situações especiais, como durante infecções graves;

- A categoria "outros tipos de DM" contém várias formas de $D M$, decorrentes de defeitos genéticos associados com outras doenças ou com uso de fármacos diabetogênicos;

- DM gestacional é a diminuição da tolerância à glicose, de magnitude variável, diagnosticada pela primeira vez na gestação, podendo ou não persistir após o parto. Abrange os casos de DM e de tolerância à glicose diminuída detectados na gravidez;

- Os estágios do DM ocorrem em todos os tipos, sendo que no tipo 1 o período de tempo entre estágios é mais curto."

Quadro 2.1 - Classificação do Diabetes Mellitus

- Tipo 1: destruição da célula beta, geralmente ocasionando deficiência absoluta de insulina de natureza auto-imune ou idiopática.

- Tipo 2: varia de uma predominância de resistência insulínica com relativa deficiência de insulina, a um defeito predominantemente secretório, com ou sem resistência insulínica.

\section{- Outros tipos específicos:}

Defeitos genéticos funcionais da célula beta

Defeitos genéticos na ação da insulina

Doenças do pâncreas exócrino

Endocrinopatias

Induzidos por fármacos e agentes químicos

Infecções

Formas incomuns de diabetes imuno-mediado

Outras síndromes genéticas geralmente associados ao diabetes

\section{Diabetes gestacional}

Fonte: CBD (2000). 


\subsection{Prevalência}

Segundo Reiner (1977), com a sétima posição, em uma lista de causas de morte por doenças nos Estados Unidos, o DM é considerado o maior problema de saúde, existindo 2,4 milhões de casos diagnosticados e cerca de 1,6 milhões de não diagnosticados, sendo a proporção de 01 paciente portador desta patologia para cada 50 pessoas; com 250 mil novos casos diagnosticados anualmente. Em 1982, Ryan \& Bronstein já apontavam, em seu trabalho, que $1,5 \%$ da população apresentava DM, exceto em indivíduos acima da faixa etária de 60 anos de idade, nos quais esses valores chegam a 10\% desta população. CUTLER, em 1985, já indicava, aproximadamente, 6 milhões de pessoas afetadas pela doença, chegando em 2001, segundo Lalla \& D'Ambrósio, a 16 milhões, ou seja, 6\% da população dos Estados Unidos, com aproximadamente 800 mil novos casos diagnosticados a cada ano.

Gregori et al. (1999) citaram que, aproximadamente, 7\% dos habitantes do mundo ocidental apresentam esta patologia, enquanto Sonis et al. (1996) relataram que cerca de 200 milhões de pessoas em todo mundo possui diabetes, afetando 17 em cada 1.000 pessoas entre os $25 \mathrm{e}$ 44 anos; e em idade acima de 65 anos, 79 indivíduos a cada 1.000 .

No Brasil, um estudo multicêntrico realizado em 1987, abrangendo nove capitais, em indivíduos de 30 a 69 anos, permitiu avaliar sua prevalência em $7,6 \%$ da população urbana de nosso país (Brasil, 2001). Fraige Filho (1999) frisou em seu artigo que em São Paulo este valor foi 
ainda mais elevado: $9,66 \%$, dos quais $46,5 \%$ desconheciam previamente essa condição, sendo somente informados no momento da aferição glicêmica. Além disso, constatou-se que, dos casos previamente conhecidos, $22,3 \%$ não realizavam qualquer tipo de tratamento ou acompanhamento médico.

Em 2001, no Brasil, em levantamento prévio na população acima de 40 anos, o Ministério da Saúde, através da Campanha Nacional de Detecção de suspeitos de Diabetes Mellitus, identificou 2,9 milhões de suspeitos de serem portadores de diabetes, o que corresponde a $14,66 \%$ da população estudada. Estes suspeitos iriam ter seus testes confirmados pelas Secretarias Municipais de Saúde.

Este número pode estar aumentando devido ao aumento da expectativa de vida dos pacientes e do aperfeiçoamento dos recursos de elucidação diagnostica.

O diabetes tipo 2, denominado antigamente de diabetes do adulto ou não-insulino-dependente, segundo citado por Mattson \& Cerutis (2001) em seu artigo de revisão de literatura do DM, é reconhecido como o tipo de maior prevalência na população, sendo responsável por cerca de $85 \%$ a $90 \%$ dos casos da doença, acometendo $10 \%$ da população acima dos 65 anos; sendo 80\% obesos. Estudo realizado em finlandeses, em 1992 , observaram que $97 \%$ dos pacientes tipo 2 manifestaram a doença após os 40 anos de idade (Eriksson et al., 1992). Munroe (1983) citou a obesidade e dieta como fatores predisponentes. Para Hother-Nielsen et al. (1988), a associação entre idade e risco do diabetes está mediada pela questão da 
obesidade, que aumenta após os 40 anos de idade. Obesidade e velhice são fatores de risco também citados no trabalho de Sonis et al. (1996). Para Service et al. (1997) idade superior a 20 anos e ausência de episódio agudo de cetoacidose são indicadores de diabetes do tipo 2. A idade de forma isolada parece que não define a classificação, mas se aliada a outras variáveis como obesidade e ausência de cetoacidose podem sugerir o tipo de diabetes, segundo Kitabchi et al. (2001).

Quanto à hereditariedade, Munroe (1983) alegou que o fator genético é uma importante consideração, sendo comum observar que parentes diabéticos têm maior probabilidade de ter filhos diabéticos. Sonis et al. (1996, p.115) diz "que os parentes de pacientes com diabetes são duas vezes e meia mais suscetíveis a desenvolver a doença, do que a população em geral". Outro estudo realizado por Li (2001) alegou que agregação familiar do diabetes tipo 2 é mais comum do que no tipo 1 , entretanto a prevalência do diabetes tipo 1 é duas vezes maior em famílias com tipo 2, sugerindo uma possível interação genética entre os dois tipos de diabetes.

\subsection{Diagnóstico}

O diagnóstico em pessoas que apresentam os sintomas clássicos, como: poliúria, polidipsia, polifagia, emagrecimento, entre outros, não apresenta dificuldade, segundo Costa \& Almeida Neto (1998), pois são característicos das condições de uma dosagem de glicose elevada no sangue. Porém, quando os sintomas clínicos não são evidentes e existe a 
suspeita, faz-se necessária uma investigação laboratorial para a confirmação do diagnóstico. Segundo estes autores, a Associação Americana de Diabetes e "National Institutes of Health", têm como critério o exame de glicemia em jejum e o teste de tolerância à glicose oral (GTT Oral ou curva glicêmica).

No exame de glicemia em jejum os valores normais são dados em até $110 \mathrm{mg} / \mathrm{dl}$, considerando-se alterada quando os valores forem de $110 \mathrm{a}$ $125 \mathrm{mg} / \mathrm{dl}$, sendo que deverão ser realizados em duas ocasiões distintas (ou seja, 2 exames em dias diferentes). Neste caso recomenda-se o teste de tolerância a glicose oral para a confirmação de diabetes.

O diagnóstico de diabetes se dará quando os valores de glicemia sangüínea forem iguais ou maiores que $126 \mathrm{mg} / \mathrm{dl}$, também em duas ocasiões distintas.

No exame de teste de tolerância à glicose oral, o paciente deverá estar em jejum; onde será colhida uma amostra de sangue para determinar a glicemia. Após ingere uma solução contendo 1,75g de glicose por $\mathrm{Kg}$ de peso, ou até no máximo de $75 \mathrm{~g}$ de glicose, colhendo-se posteriormente amostras de sangue 1 e 2 horas após a ingestão desta solução, para determinar os níveis de glicose. Os valores de referência são apresentados no Quadro 2.2. 
Quadro 2.2 - Valores da glicose plasmática (em mg/dl) para diagnóstico de Diabetes Mellitus e seus estágios pré-clínicos

\begin{tabular}{|c|c|c|c|}
\hline Categoria & Jejum* & $\begin{array}{c}2 \mathrm{~h} \text { após } \\
75 \mathrm{~g} \text { glicose }\end{array}$ & Casual $^{* *}$ \\
\hline $\begin{array}{c}\text { Glicose de jejum } \\
\text { alterada }\end{array}$ & $>110 \mathrm{e}<126$ & $<140$ & \\
\hline $\begin{array}{c}\text { Tolerância à } \\
\text { glicose diminuída }\end{array}$ & $<126 \mathrm{e}$ & $\geq 140$ e $<200$ & \\
\hline Diabetes Mellitus & $\geq 126$ ou & $>200$ ou & $\begin{array}{c}\geq 200 \\
\text { (com sintomas clássicos) }\end{array}$ \\
\hline & & & Fonte: CBD (2000). \\
\hline
\end{tabular}

\subsection{Manifestações sistêmicas}

Segundo Costa \& Almeida Neto (1998), a maioria das pessoas com diabetes tipo 2 pode herdar de seus familiares uma alteração dos receptores de insulina em músculos, tecido gorduroso, fígado, entre outros, que propicia o aumento de insulina no sangue. Este é agravado pela falta de exercícios e excesso ou erro alimentar contribuindo para o aumento do peso corporal. Com isso a glicose começa aumentar, principalmente após a alimentação (intolerância à glicose oral). A hiperglicemia mantida pode levar a glicotoxicidade em todos os tecidos e também nas células que fabricam insulina no pâncreas e conseqüente redução de sua fabricação. Com isso 
temos a glicemia de jejum aumentada, caracterizando o diabetes. Estes autores alegam ainda que existem algumas situações que, por atuarem de alguma forma na produção ou ação de insulina, favorecem, naqueles já predispostos, o aparecimento de diabetes. Entre elas podemos destacar: obesidade, infecções, gravidez, cirurgias, traumas emocionais, estresse e envelhecimento. $\mathrm{O}$ uso de medicamentos diabetogênicos em doses altas e por tempo prolongado, como cortisona e derivados, alguns diuréticos, betabloqueadores, estrógenos, também irão favorecer o aparecimento do diabetes.

Houaiss et al. (1987) dizia que o diagnóstico clínico é comumente feito quando da presença de sintomas clássicos da doença como poliúria, polodipsia, polifagia, emagrecimento e, nos casos mais graves, desidratação, acidose e distúrbios no nível de consciência, associados a alta taxa de glicose na urina (glicosuria). Para Barcellos et al. (2000) esses sintomas e a ausência do controle metabólico adequado levam a complicações crônicas como as macroangiopatias, microangiopatias, neuropatias, nefropatias, retinopatias; sintomas e complicações essas que irão influenciar no tratamento adequado desses pacientes, principalmente quando do exame pré-operatório, em que a prevenção de infecções e dos distúrbios metabólicos, durante as consultas, são extremamente importantes.

Lauda et al. (1998) diziam que a crise hiperglicêmica (aumento da taxa de glicose na corrente sangüínea) pode ocorrer durante o atendimento deste paciente, sendo geralmente limitada aos insulino-dependentes. A 
elevação prolongada da glicose sangüínea pode causar uma acidose metabólica que pode levar a coma, se não tratado. À crise de hipoglicemia (diminuição da taxa de glicose na corrente sangüínea) é o mais comum problema médico encontrado em consultório. Os clássicos sinais e sintomas são: taquicardia, palpitação, sudorese, tremor, náuseas e fome. Se não for diagnosticada e tratada pode levar a sérios problemas como o coma e consequentemente a morte.

\subsection{Manifestações bucais}

Seiffer (1862) citado por Sonis et al., (1996) foi o primeiro a descrever a associação entre as alterações bucais e o diabetes. Para Löe (1993) e lacopino (1995), o DM também é um importante fator de repercussão para a saúde bucal, tendo a doença periodontal sido apontada como sua sexta complicação mais prevalente. Acreditam que a incidência de periodontite associada ao DM cresce a uma taxa anual de $6 \%$. Segundo Sonis et al. (1996) a periodontite é a complicação predominante no paciente portador de

$\mathrm{DM}$, estando associada à presença de placa bacteriana e cálculo, geralmente acompanhada por coleção purulenta, e levando a grande reabsorção óssea. Para Solis et al. (2001) a doença periodontal esta relacionada ao estresse, visto que nesta situação ocorre diminuição da função imunológica. "Polimorfismos em genes de mediadores próinflamatórios, que caracterizam a resposta do hospedeiro, têm sido alvo de estudos recentes, que objetivam diagnosticar precocemente o mecanismo 
da doença" (Trevillato et al., 2001), associando-a como doença auto-imune. Para Enrich et al. (1991) a probabilidade do paciente com DM desenvolver está patologia é três vezes maior do que em pacientes não diabéticos.

A gengivite, segundo Ervasti et al. (1985), também está relacionada com o pobre controle metabólico e associada com alterações vasculares.

Rees (1994), em sua revisão sobre alterações orais em pacientes diabéticos, relata que a severidade das manifestações orais e o aumento de sua freqüência, entre elas a cárie, está relacionada com a descompensação do diabetes. Alguns autores relatam que a alta incidência de cáries em pacientes com DM ocorre devido ao aumento da glicose salivar, naqueles com pobre controle metabólico, sendo que as cáries cervicais ocorrem com maior freqüência nos pacientes portadores de diabetes tipo 2, devido a ingestão de carboidratos (Bacic et al., 1989; Joshipura et al., 1991; Li et al., 1999).

Estudo realizado por Stefaniotis \& Donta, em 1990, com 150 pacientes portadores de DM tipo 2 observou-se que $76 \%$ apresentavam xerostomia ou hiposalivação. Discute, ainda, que os valores glicêmicos do paciente podem ser responsável por esta manifestação e não o tempo de duração da diabetes. A hiposalivação ocorre em várias situações, sendo sua avaliação muitas vezes subjetiva, mas existem escores como o de Tarzia (1993) que definem estes valores em normais ou anormais (Magalhães et al., 1999). Para Ueta et al., (1993) com a diminuição do fluxo salivar há maior predisposição à proliferação de fungos, principalmente a candidíase, visto que a saliva possui $\lg \mathrm{A}$ e componentes secretórios livres que inibem a 
adesão da cândida às células epiteliais. Diz também que a hiperglicemia altera a capacidade oxidativa do neutrófilo com potencial de debelar a candidíase.

\subsection{Conduta clínica}

Acredita-se que a conduta clínica deve saber basear-se no diagnóstico, na prescrição e no manejamento correto do paciente portador de DM, eliminando os riscos de complicações e melhorando a qualidade de vida. Os pacientes portadores de diabetes têm sua resistência reduzida, propiciando desta forma infecções. Segundo Rocha et al. (2002), há uma maior incidência de infeções específicas, muitas vezes com maiores taxas de complicações e maior severidade. Além disso, há também alguns quadros infecciosos quase exclusivos do diabético, sendo a outra face da situação as freqüentes descompensações do próprio DM frente aos quadros infecciosos. As microangiopatias, acidose metabólica, com fagocitose ineficaz por macrófagos, segundo alguns autores, facilita o aumento da presença das infecções (Amato Neto, 1999; Carraza Jr., 1997). Para tanto, é necessário saber quais os problemas apresentados por estes pacientes diferenciando-os dos pacientes normoglicêmicos (Lauda et al., 1998). Em 1968 a fragilidade do manejo do paciente diabético no atendimento odontológico em hospital já é citada por Shulkin \& Weinberg, orientando, também, quanto à necessidade de uma tríade para o atendimento, formada por um médico, cirurgião dentista e anestesiologista, onde alertam que a 
compreensão do problema e a experiência desta equipe será essencial para o sucesso do procedimento cirúrgico. Reiner (1977) em seu estudo relatou também a necessidade de um trabalho conjunto entre paciente, médico e dentista no controle do diabetes e alerta para que o paciente não seja submetido a cirurgia oral, em consultório, se estiver descompensado.

Cheraskin \& Ringsdor (1971), em seu artigo, citaram trabalho de Znamensky de 1902, onde este já observa a associação entre DM e infecção periodontal, demonstrando, desta forma, a preocupação desta relação. Relatam ainda a necessidade de um planejamento mais realista associando metabolismo dos glicídeos com parâmetros periodontais.

Gaberthüel \& Curilovic, em 1977, alegaram que a cavidade oral é uma área biológica sensível, em que diferentes desvios patológicos do organismo podem se manifestar de forma muito clara e precoce, e apontam para a necessidade do cirurgião dentista, como auxiliar, no reconhecimento e tratamento precoce do DM.

Reiner (1977) citou a simplicidade e a disponibilidade dos testes de urina e como estes podem proteger o paciente e o dentista. Sugere a remoção de focos infecciosos, a correção das desordens dentais e o restabelecimento da oclusão apropriando a mastigação e conduzindo, desta forma, a um estado melhor de controle.

Munroe em 1983, relatou a importância do cirurgião dentista como um agente de saúde, visto que no cuidado com a anamnese alguns sinais e sintomas físicos podem ser indicadores da presença do DM, cabendo ao profissional encaminhar este paciente para atendimento médico. A 
necessidade do levantamento da história médica do paciente e a observação dos sinais e sintomas da hipoglicemia durante o transcurso clínico são ressaltados por Cutler (1985), recomendando a classificação do paciente, após consulta ao médico e dos exames complementares, em categorias de risco, de acordo com as condições sistêmicas. Estas recomendações também são sugeridas por Sonis et al. (1996), que acrescentam, ainda, a redução do estresse, instruções sobre a dieta e redução do risco de infecção para contribuir no controle do tratamento. Gregori et al. em 1999, propõe a aplicação da anamnese direcionada àqueles pacientes que relatam poliúria, polipsia, polifagia, nictúria e emagrecimento (Quadro 2.3). Na inexistência de sintomas clínicos bem definidos, sugere investigação laboratorial. Ressalta também os quadros de hipoglicemia e hiperglicemia e a necessidade de se realizar um atendimento de forma peculiar, pois a doença assume características próprias em cada indivíduo.

Justino (1988), alertou para a importância dos exames laboratoriais de rotina, os quais se constituem em valioso instrumento, não só para o diagnóstico de doenças, mas também para orientação da terapêutica e proservação do paciente. 
Quadro 2.3 - Anamnese direcionada para o DM, segundo Gregori

1. Você é diabético ?

( ) Sim ( ) Não ( ) Não sei

2. Alguém de sua família tem diabetes ?

( ) Sim ( ) Não ( ) Não sei

3. Você toma muito líquido?

( ) Sim ( ) Não ( ) Não sei

3.1 Com resposta positiva, procurar definir quanto, em copos por dia.

4. Tem muita fome?

( ) $\operatorname{Sim}($ ) Não ( ) Não sei

5. Come muitos doces?

( ) Sim ( ) Não

6. Urina muito?

( ) Sim ( ) Não

7. A sua cicatrização é demorada ?

( ) Sim ( ) Não

Fonte: RPG (1999)

Galili et al. em 1994, exalta a responsabilidade do profissional quanto ao bem estar físico e psicológico do paciente portador de diabetes, sendo a comunicação com o médico que atende este paciente essencial para este sucesso. Relata, também, a importância dos glicosímetros no atendimento, para a verificação dos níveis de glicose, possibilitando melhor controle, assim como conhecer as medicações antidiabetogênicas e seus efeitos farmacodinâmicos. Cuidados estes também sugeridos por Barcellos et al. (2000) em seu artigo, onde dizem que os pacientes portadores de DM representam um grupo especial, o que requer atenção e a aplicação de medidas preventivas, curativas e terapêuticas específicas, pois os sintomas apresentados podem influenciar no tratamento adequado, principalmente quando do exame pré-operatório, sendo extremamente importantes a 
prevenção de infecções e dos distúrbios metabólicos durante as consultas. Sugerem, também, que o dentista deva estar preparado no que tange a materiais específicos no atendimento destes pacientes, como glicosímetro, fitas reagentes, estilete descartável, esfignomanometro, soluções contendo glicose a 20\%, insulina regular e seringas para insulina, para um atendimento mais seguro.

Cherubini et al. (2000), em seu estudo, alegam que o dimensionamento das condições sistêmicas e dos agravos bucais experimentados pelos pacientes portadores de diabetes deve instruir os profissionais da saúde bucal quanto ao tipo de atendimento demandado. Preconizam, ainda, a partir deste estudo a avaliação glicêmica, a aferição da pressão arterial e exames clínicos e complementares necessários antes de procedimentos invasivos. Para Carboni (2001) o plano de tratamento irá depender do controle glicêmico e das limitações sistêmicas que o paciente pode apresentar, tais como cardiopatias e nefropatias. Citou a importância da anamnese minuciosa e exame clínico cuidadoso, além da solicitação de exames complementares como glicemia em jejum, hemoglobina glicada, hemograma e coagulograma completo, como também troca de informações com o médico que cuida do controle glicêmico deste paciente. $\mathrm{O}$ autor cita ainda que o conhecimento profundo da patologia por parte dos cirurgiões dentistas facilita o atendimento odontológico destes pacientes.

Mattson \& Cerutis em 2001, alegaram que devido ao grande número de pacientes portadores de DM, é necessário o cirurgião dentista conhecer os tipos de diabetes, bem como traçar um plano de tratamento adequado e 
saber das possibilidades de resultado do tratamento, assim como suas complicações.

Lalla \& D'Ambrosio em 2001, relataram que o DM pode ter um impacto significativo na saúde bucal. Sendo importante que os dentistas estejam familiarizados com a gerência médica destes pacientes, reconhecendo os sinais e os sintomas dos não diagnosticados ou mal controlados. Declararam a necessidade de um papel ativo do cirurgião dentista no diagnóstico e no tratamento das circunstâncias orais associadas com o DM, contribuindo para o controle e manutenção da saúde. 


\section{PROPOSIÇÃO}

\subsection{Proposição geral}

Caracterizar as alterações sistêmicas e as manifestações bucais apresentadas pelos pacientes portadores de diabetes tipo 2 no momento em que se apresentam para atendimento odontológico, condições estas que podem interferir no atendimento seguro destes pacientes.

\subsection{Proposição específica}

1- Rever a bibliografia pertinente à definição, classificação, diagnóstico, manifestações sistêmicas e bucais dos pacientes portadores de Diabetes Mellitus.

2- Coletar dados sobre avaliação auto-referida de saúde sistêmica e bucal, aferir pressão arterial e índice de glicemia capilar e efetuar exame clínico bucal destes pacientes.

3- Subsidiar o atendimento odontológico com informações que norteiem o profissional, de forma a colaborar na diminuição do número de intercorrências no momento do atendimento clínico a estes pacientes. 


\section{MATERIAL E MÉTODO}

\subsection{Fonte de dados}

Durante a 4ํㅡㄹ Campanha Nacional gratuita de prevenção, educação e detecção em diabetes realizada pela Associação Nacional de Assistência ao Diabético (ANAD), no ano de 2001, no Colégio Madre Cabrini, na cidade de São Paulo, Brasil, foram realizados aproximadamente 10.000 exames de teste de glicemia capilar na população. Destes, após o exame da glicemia, os que já tinham diagnóstico previamente confirmado eram encaminhados para exames com oftamologista, clínico geral (para aferição da pressão arterial), otorrinolaringologista (para verificar acuidade auditiva) e cirurgiões dentistas para verificar as condições de saúde bucal.

Foram encaminhados para avaliação bucal 478 participantes, destes 372 eram portadores de Diabetes Mellitus tipo 2; sendo que 191 eram do sexo masculino e 181 do sexo feminino, com idade entre 32 a 87 anos. 


\subsection{Método}

Primeiramente os participantes respondiam a um questionário aplicado por 3 cirurgiões dentistas, contendo informações auto-referidas sobre antecedentes familiares com diabetes, medicação em uso e alterações metabólicas pré-existentes como cardiopatias, retinopatias, neuropatias, nefropatias, angiopatias e hipertensão arterial. Sendo transcrito para esta ficha, também, o valor da glicemia e da pressão arterial, realizada no dia da Campanha, e se estava em jejum (Anexo A).

Foi perguntado aos participantes se estavam sob acompanhamento médico e também odontológico; sendo considerado como acompanhamento a última visita ao profissional médico com período inferior a 6 meses, e odontológico com período inferior a 1 ano.

Foi questionado se o participantes já haviam informado alguma vez ao seu dentista que eram portadores de diabetes. No caso de resposta negativa, solicitamos que justificasse. No caso de resposta positiva, foi perguntado se o profissional tinha informado alguma vez sobre a importância dos cuidados da cavidade bucal no controle da glicemia.

Procurou-se ainda verificar a percepção do paciente quanto ao seu estado de saúde bucal, solicitando que ele a classificasse em: muito satisfatória, satisfatória, nem satisfatória/nem insatisfatória, insatisfatória ou muito insatisfatória.

Posteriormente estes participantes eram encaminhados a outra sala onde era realizado exame clínico bucal por 16 estudantes de odontologia 
previamente treinados, formando 8 duplas, sendo um examinador e outro anotador, os quais se alternavam entre os exames e tendo um cirurgião dentista como supervisor. Todos os estudantes estavam paramentados com avental, gorro, luva e máscara para realização do exame clínico, o qual foi realizado com espátulas de madeira e com iluminação natural.

As manifestações bucais pesquisadas foram: dor no momento do atendimento, queilite angular, gengivite, relato de diminuição de fluxo salivar (boca seca), cálculo salivar, candidíase eritematosa (associada ao uso de prótese), exposição radicular com sensibilidade, abscesso gengival, herpes simples em fase aguda, mobilidade, extrusão e abrasão dental, raiz residual, hálito cetônico (subjetivo), hiperplasia gengival, sangramento e ulcerações.

A presença de hiposalivação foi constatada através da mensuração do fluxo salivar não estimulado por 5 minutos, utilizando os parâmetros sugeridos por Tarzia (1993) e realizado somente nos participantes que relatavam este quadro. A saliva foi depositada em um copo plástico descartável e posteriormente o volume foi aferido em seringa Luer.

A gengivite foi diagnosticada segundo os critérios propostos por Lascala \& Moussalli (1989) e a avaliação da condição dentária, quanto ao histórico da manifestação de cárie, foi efetuada através do índice de CPO-D (World Health Organization, 1997). Uso, necessidade de próteses e tempo de uso foram outro fator observado, além da coleta de relatos dos participantes informando o motivo de não declarar ao cirurgião dentista que eram portadores de diabetes; sendo realizada transcrição destes 
depoimentos, que poderão subsidiar os profissionais quando do preenchimento da anamnese.

Todos os sujeitos pesquisados foram informados verbalmente sobre os objetivos do estudo e expressaram sua concordância em participar assinando o termo de consentimento (Anexo B). O protocolo de pesquisa foi avaliado e aprovado pelo Comitê de Ética em Pesquisa da Faculdade de Odontologia da Universidade de São Paulo (Anexo C).

Os dados obtidos foram processados através de análise estatística voltada à caracterização da distribuição das manifestações sistêmicas e orais no grupo estudado, reunindo, desta forma, informações que norteiem o atendimento odontológico aos pacientes portadores de diabetes tipo 2 , colaborando para diminuir o número de intercorrências. 


\section{RESULTADOS}

\subsection{Distribuição por sexo}

Como podemos observar na tabela a seguir (Tabela 5.1), 51,5\% eram do sexo masculino e $48,5 \%$ do sexo feminino, sendo distribuídos por faixa etária.

A maior concentração de participantes ficou na faixa etária entre 55 a 64 anos (33,5\%), seguido da faixa etária entre 65 a 74 anos $(26,0 \%)$ e entre 45 a 54 anos $(24,5 \%)$.

Tabela 5.1 - Distribuição do sexo por faixa etária

\begin{tabular}{|c|c|c|c|c|c|c|}
\hline & \multicolumn{4}{|c|}{ SEXO } & \multicolumn{2}{|c|}{$\overline{\text { TOTAL }}$} \\
\hline & \multicolumn{2}{|c|}{ Masculino } & \multicolumn{2}{|c|}{ Feminino } & \multirow[b]{2}{*}{ no } & \multirow[b]{2}{*}{$\%$} \\
\hline & no & $\%$ & no & $\%$ & & \\
\hline \multicolumn{7}{|l|}{ FAIXA ETÁRIA } \\
\hline Inferior a 35 anos & 1 & $0,5 \%$ & 2 & $1,0 \%$ & 3 & $1,0 \%$ \\
\hline 35- 44 anos & 11 & $6,0 \%$ & 14 & $8,0 \%$ & 25 & $7,0 \%$ \\
\hline 45- 54 anos & 52 & $27,0 \%$ & 40 & $22,0 \%$ & 92 & $24,5 \%$ \\
\hline $55-64$ anos & 57 & $30,0 \%$ & 68 & $37,5 \%$ & 125 & $33,5 \%$ \\
\hline $65-74$ anos & 51 & $26,5 \%$ & 46 & $25,5 \%$ & 97 & $26,0 \%$ \\
\hline 75 ou mais & 19 & $10,0 \%$ & 11 & $6,0 \%$ & 30 & $8,0 \%$ \\
\hline TOTAL & $\begin{array}{c}191 \\
(51,5 \%)\end{array}$ & & $\begin{array}{c}181 \\
(48,5 \%) \\
\end{array}$ & & $\begin{array}{c}372 \\
(100,0 \%)\end{array}$ & \\
\hline
\end{tabular}




\subsection{Alteração glicêmica}

Dos participantes avaliados, 285 apresentavam alteração glicêmica no momento do exame, sendo 146 do sexo masculino $(76,4 \%)$ e 139 do sexo feminino (77,0\%). A análise da alteração glicêmica, no Gráfico 5.1, também foi realizada por sexo e por faixa etária. Observamos também que não houve discrepância expressiva entre os níveis de alterações glicêmicas entre sexo e por faixa etária.

\section{$\square$ Masculino $\square$ Feminino}

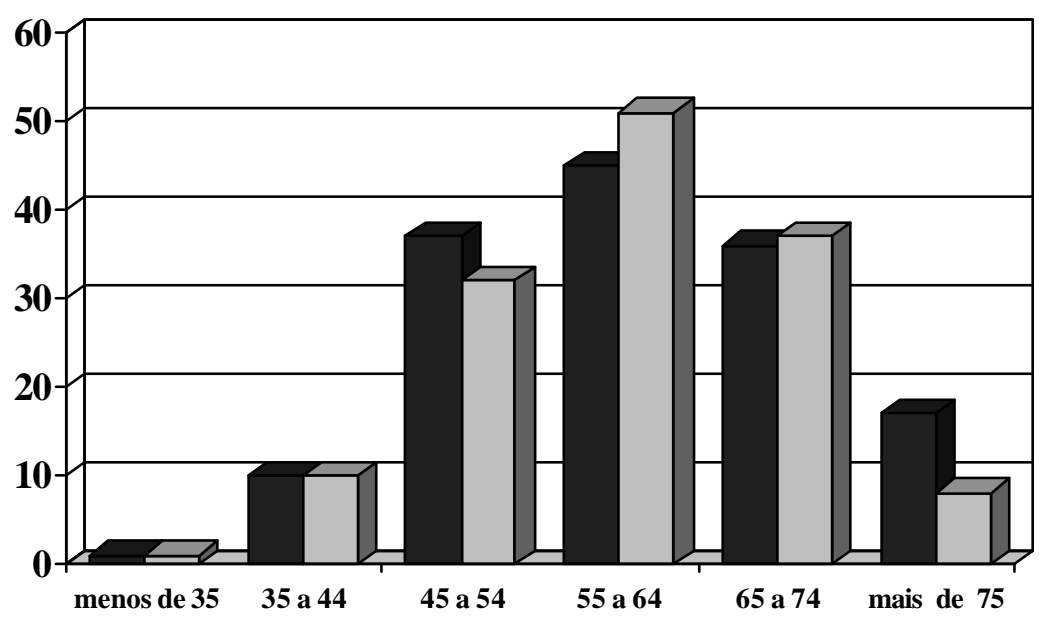

Gráfico 5.1 - Alteração da glicemia por sexo e faixa etária(em anos)

\subsection{Antecedentes familiares com diabetes}

Analisando os dados dos participantes, observamos que 242 (65\%) possuíam familiares com diabetes, enquanto 130 (35\%) não possuíam qualquer familiar com esta patologia (Tabela 5.2). 


\subsection{Uso de medicação para o controle do diabetes}

Quanto ao uso da medicação para controle da glicemia, observamos que 230 pacientes (62\%) faziam uso de hipoglicemiantes orais, enquanto 59 (16\%) faziam uso regular de insulina. Destes, $6 \%$ faziam uso associado de hipoglicemiantes orais e insulina para controle (Tabela 5.2).

Tabela 5.2 - Participantes com antecedentes familiares com diabetes e os que faziam uso de medicação para controle (valores absolutos e porcentagem)

\begin{tabular}{l|r|c}
\hline & no & $\%$ \\
\hline Antecedente familiar & 242 & $65 \%$ \\
Insulina & 59 & $16 \%$ \\
Hipoglicemiante oral & 230 & $62 \%$ \\
Uso Associado & & $6 \%$ \\
(hipoglicemiante + insulina) & 21 & \\
\hline
\end{tabular}

\subsection{Acompanhamento médico}

Conforme Tabela 5.3, podemos observar que grande parte dos participantes realizam acompanhamento médico, sendo considerando desta forma os que tinham passado pelo serviço com período inferior a 06 meses. Dos participantes avaliados, 296 realizavam acompanhamento médico (80\%), sendo que destes, 181 participantes $(61,0 \%)$ realizavam acompanhamento no Sistema Único de Saúde - SUS, enquanto 91 
participantes $(31,0 \%)$ realizavam em convênios e 24 (8,0\%) em médicos particulares. Um dos participante $(0,5 \%)$ não respondeu a pergunta.

Tabela 5. 3 - Participantes em acompanhamento médico e sua distribuição nos serviços

\begin{tabular}{l|c|c}
\hline Acompanhamento médico* & Total & $\%$ \\
\hline SUS & 181 & $61,0 \%$ \\
Convênio & 91 & $31,0 \%$ \\
Particular & 24 & $8,0 \%$ \\
Não respondeu & 01 & 0,5 \\
\hline TOTAL & $296(80 \%)$ & $100 \%$ \\
\hline 04 casos de múltipla entrada de pacientes que utilizavam simultaneamente \\
SUS/convênio e SUS/particular.
\end{tabular}

\subsection{Acompanhamento odontológico}

Observamos, conforme Tabela 5.4, que diferentemente do acompanhamento médico, somente 138 dos participantes (37,0\%), realizaram consulta odontológica com período inferior a 1 ano. Quanto à procura por atendimento, este se concentrou nos consultórios particulares; 103 pacientes (74,5\%), sendo seguido pelo SUS com 17 pacientes (12,5\%) e pelos convênios com 10 participantes (7,0\%). Do restante, 08 participantes (6,0\%) não responderam. 
Tabela 5.4 - Participantes em acompanhamento odontológico e sua distribuição nos serviços

\begin{tabular}{l|c|c}
\hline Acompanhamento odontológicos & Total & $\%$ \\
\hline SUS & 17 & $12,5 \%$ \\
Convênio & 10 & $7,0 \%$ \\
Particular & 103 & $74,5 \%$ \\
Não respondeu & 8 & $6,0 \%$ \\
\hline TOTAL & $138(37 \%)$ & $100 \%$ \\
\hline
\end{tabular}

\subsection{Informação do pacientes ao cirurgião dentista}

Alguns participantes não informam aos seus cirurgiões dentistas que são portadores de diabetes, por uma série de alegações.

$\mathrm{Na}$ Tabela 5.5 demonstramos esta falta de informação e posteriormente transcrevemos alguns depoimentos destes participantes, que tentam justificar o motivo desta omissão.

Dos participantes questionados, 250 (67,0\%) informam ao seu dentista serem portadores de diabetes, enquanto 91 pacientes $(24,5 \%)$ não informam, e 31 (8,5\%) não responderam. 
Tabela 5.5 - Informação ao CD sobre ser portador de diabetes

\begin{tabular}{l|c|c}
\hline Informação ao Cirurgião dentista & n & $\%$ \\
\hline Sim & 250 & $67,0 \%$ \\
Não & 91 & $24,5 \%$ \\
Não respondeu & 31 & $8,5 \%$ \\
\hline TOTAL & 372 & $100 \%$ \\
\hline
\end{tabular}

O que mais nos chamou a atenção neste dado foi à falta de informação dos participantes quanto à importância do profissional cirurgião dentista ter conhecimento desta patologia. Com isso apresentamos o perfil de alguns participantes e transcrevemos seus depoimentos que serão importantes em nossa discussão; pois explicam o porquê da decisão de informar ou não o cirurgião dentista que são portadores de DM.

5.7.1 Transcrições de depoimentos

5.7.1.1 - O que leva os participantes a não informarem o cirurgião dentista que são portadores de diabetes

\section{Participante 1}

Perfil: 69 anos de idade, sexo feminino, portadora de diabetes há 12 anos, descompensada, faz uso de hipoglicemiante oral e insulina para o controle da diabetes e usuária de prótese total superior e inferior há 20 anos. 
Resposta: "...não informo por que faço uso de dentadura em cima e embaixo..."

\section{Participante 2}

Perfil: 54 anos de idade, sexo masculino, portador de diabetes há 10 anos, não faz uso de medicação para o controle da diabetes, hipertenso e usuário de prótese removível inferior.

Resposta: "...nunca me preocupei em informar o dentista..."

\section{Participante 3}

Perfil: 53 anos de idade, sexo masculino, portador de diabetes há 10 anos, descompensado e fazendo uso de hipoglicemiante oral para o controle da diabete.

Resposta: "...não vejo relação entre o diabetes e o dentista..."

\section{Participante 4}

Perfil: 69 anos de idade, sexo masculino, portador de diabetes há 02 anos, não faz uso de medicação para controle da glicemia, hipertenso e usuário de prótese total superior.

Resposta: "...não acho necessário..."

\section{Participante 5}

Perfil: 71 anos, sexo feminino, portadora de diabetes há 08 anos, faz uso de hipoglicemiante oral e insulina para o controle da diabetes cardiopata. 
Resposta: "...não informaria o dentista, pois teria medo de não ser tratada..."

\section{Participante 6}

Perfil: 65 anos, sexo feminino, portadora de diabetes há 08 anos, fazendo uso de hipoglicemiantes orais para o controle da diabete e usuária de prótese total superior e prótese removível inferior.

Resposta: "...não sabia que tinha que falar..."

\section{Participante 7}

Perfil: 68 anos, sexo masculino, portador de diabetes a 14 anos, não faz uso de medicação para o controle da diabetes e hipertenso.

Resposta: "...diabetes não tem nada a haver com a boca..."

\section{Participante 8}

Perfil: 38 anos de idade, sexo masculino, portador de diabetes a 03 anos, faz uso de hipoglicemiante oral e insulina para controle da diabetes e descompensado.

Resposta: "...esqueço de dizer..."

\section{Participante 9}

Perfil: 51 anos, sexo masculino, portador de diabetes a 01 ano, não faz uso de medicação para controle da diabetes, descompensado e não realiza acompanhamento médico. 
Resposta: "...por que o dentista nunca perguntou..."

5.7.1.2 - O que leva os participantes a informarem o cirurgião dentista que são portadores de diabetes

\section{Participante 1}

Perfil: 63 anos, sexo masculino, portador de diabetes há 10 anos, faz uso de hipoglicemiante oral para o controle do diabetes, descompensado e hipertenso.

Resposta: "...somente por que o dentista perguntou..."

\section{Participante 2}

Perfil: 54 anos, sexo feminino, portadora de diabetes há 14 anos, faz uso de hipoglicemiante oral e insulina para controle do diabetes, descompensada, possui neuropatia e portadora de prótese total superior.

Resposta: "...por causa do anestésico..."

\section{Participante 3}

Perfil: 51 anos, sexo masculino, portador de diabetes há 05 anos, não faz uso de medicação, está em acompanhamento médico, descompensado e usuário de prótese total superior.

Resposta: "... por que o paciente diabético necessita de tratamento especial devido aos riscos..." 


\section{Participante 4}

Perfil: 64 anos, sexo feminino, portadora de diabetes há 15 anos, faz uso de hipoglicemiante oral e insulina para controle do diabetes, possui retinopatia e hipertensão, descompensada e usuária de prótese parcial removível superior.

Resposta: "... devido as inflamações bucais..."

\section{Participante 5}

Perfil: 58 anos, sexo masculino, portador de diabetes há 07 meses, não faz uso de medicação para o controle do diabetes, descompensado, apresenta neuropatia e hipertensão.

Resposta: "...acha importante informar..."

\section{Participante 6}

Perfil: 76 anos, sexo feminino, portadora de diabetes há 06 anos, faz uso de hipoglicemiante oral para o controle do diabetes, descompensada, hipertensa, portadora de prótese total superior e inferior.

Resposta: "...sempre informo ao dentista que está me tratando..."

\section{Participante 7}

Perfil: 61 anos, sexo feminino, portadora de diabetes há 02 anos, faz uso de hipoglicemiante oral para o controle do diabetes e compensada.

Resposta: "...informo se o dentista perguntar..." 


\subsection{Informação do cirurgião dentista aos pacientes sobre a importância do controle glicêmico}

Em contrapartida, tentamos verificar, através de questionamento aos participantes, se eram orientados pelos cirurgiões dentistas quanto a importância da boa condição de saúde bucal no controle da glicemia.

Dos 250 participantes (67\%) que informavam ao seu dentista que era portador de diabetes, 78 (31\%) dos profissionais orientaram quanto a este cuidado, enquanto que 157 (63\%) não orientaram. Dos participantes, 15 (6\%) não responderam (Tabela 5.6).

Tabela 5.6 - Informação do CD sobre importância da boa condição de saúde bucal no controle da glicemia

\begin{tabular}{l|c|c}
\hline Informação do Cirurgião dentista & n & $\%$ \\
\hline Sim & 78 & $31 \%$ \\
Não & 157 & $63 \%$ \\
Não respondeu & 15 & $6 \%$ \\
\hline TOTAL & $250(67 \%)$ & $100 \%$ \\
\hline
\end{tabular}

\subsection{Manifestações sistêmicas auto-referidas}

Foi solicitado aos participantes que auto-referissem, através de um questionário, as manifestações sistêmica pré-existentes. Destes, 173 relatam hipertensão arterial (46\%), 117 relataram retinopatia (31\%), 114 
relatam neuropatia (31\%), 76 relatam angiopatia $(20 \%), 72$ relatam cardiopatia (19\%), 38 relatam nefropatia (10\%) e 72 alegam não apresentar qualquer tipo de manifestação sistêmica (19\%), como observado na Tabela 5.7 .

Essas manifestações apareceram de forma isolada em alguns participantes, enquanto em outros elas estiveram associadas.

Tabela 5.7 - Manifestações sistêmicas auto-referidas pelos participantes da pesquisa

\begin{tabular}{l|c|c}
\hline \multicolumn{1}{c|}{ Manifestações } & Total & Porcentagem \\
\hline Hipertensão arterial & 173 & $46 \%$ \\
Retinopatia & 117 & $31 \%$ \\
Neuropatia & 114 & $31 \%$ \\
Angiopatia & 76 & $20 \%$ \\
Cardiopatia & 72 & $19 \%$ \\
Nefropatia & 38 & $10 \%$ \\
Sem manifestação & 72 & $19 \%$ \\
\hline
\end{tabular}

\subsection{Manifestações bucais}

Quanto aos achados das manifestações bucais, nestes participantes, observamos, conforme Tabela 5.8, que as maiores ocorrências foram: 212 participantes com exposição radicular com sensibilidade (57\%), 168 com gengivite (45\%), 164 com diminuição de fluxo salivar (44\%), 159 com cálculo salivar (42\%) e 151 participantes com abrasão dental (40\%). Em proporções 
menores apareceram: 87 participantes com mobilidade dental (23\%), $85 \mathrm{com}$ dor (22\%), 76 com extrusão dental (20\%), 67 com candidíase (18\%), 66 com sangramento gengival (17\%), $60 \mathrm{com}$ raiz residual (16\%), $58 \mathrm{com}$ hálito cetônico (15\%), 40 com queilite (10\%), 38 com hiperplasia gengival (10\%), 18 com abscesso gengival (4\%), 12 com ulceração (3\%), 10 participantes com herpes em fase aguda (2\%) e 24 não apresentavam qualquer manifestação bucal (6\%). Em relação à diminuição do fluxo salivar, estes valores foram auto-referidos.

Tabela 5. 8- Manifestações bucais encontradas nos participantes da pesquisa

\begin{tabular}{l|c|c}
\hline Manifestações & $\mathbf{n} \mathbf{0}$ & $\%$ \\
\hline Exposição radicular & 212 & $57 \%$ \\
Gengivite & 168 & $45 \%$ \\
Diminuição de fluxo & 164 & $44 \%$ \\
Cálculo salivar & 159 & $42 \%$ \\
Abrasão dental & 151 & $40 \%$ \\
Mobilidade dental & 87 & $23 \%$ \\
Extrusão dental & 76 & $20 \%$ \\
Dor & 85 & $22 \%$ \\
Candidíase & 67 & $18 \%$ \\
Sangramento gengival & 66 & $17 \%$ \\
Raiz Residual & 60 & $16 \%$ \\
Hálito cetônico & 58 & $15 \%$ \\
Queilite & 40 & $10 \%$ \\
Hiperplasia gengival & 38 & $10 \%$ \\
Abscesso gengival & 18 & $4 \%$ \\
Ulcera & 12 & $3 \%$ \\
Herpes & 10 & $2 \%$ \\
Sem manifestações & 24 & $6 \%$ \\
\hline
\end{tabular}


Realizamos aferição de fluxo salivar em 250 participantes, segundo os padrões sugeridos por Tarzia (1993), e obtivemos um total de 67 indivíduos com hiposalivação (27\%) e 5 indivíduos com xerostomia (2\%), sendo um dado interessante, a observar, que estes eram do sexo feminino (Tabela $5.9)$.

Tabela 5. 9 - Alteração do fluxo salivar

\begin{tabular}{l|c|c|c}
\hline \multicolumn{1}{c|}{ Fluxo salivar } & M & F & T \\
\hline Hiposalivação* & 28 & 39 & $67(27 \%)$ \\
Xerostomia ** $^{*}$ & 0 & 5 & $5(2 \%)$ \\
Sem manifestação & 98 & 80 & $178(71 \%)$ \\
\hline TOTAL & 126 & 124 & $250(100 \%)$ \\
\hline
\end{tabular}

avaliação de 250 pacientes

* valores inferior a $0,7 \mathrm{ml} / \mathrm{min}$ (Tarzia)

** ausência total de saliva

\subsection{Uso de prótese}

Devido à perda de elementos dentários, pelas condições de higienização ou pelos agravos da doença, observamos um número elevado de aparelhos protéticos de reabilitação. Nos participantes da pesquisa observamos que 227 (61\%) faziam uso de prótese, sendo que 149 participantes (65\%) faziam uso de prótese total superior (PTS), 66 (29\%) usavam prótese total inferior (PTI), 60 (26,5\%) usavam prótese parcial removível superior (PPRS) e 76 (33,5\%) usavam prótese parcial removível inferior (PPRI) e 145 pessoas não utilizavam estes tipos de próteses (39\%), 
conforme observado na Tabela 5.10. Houve múltiplas entradas devido ao fato de alguns participantes utilizarem próteses simultâneas.

Tabela 5.10 - Distribuição dos participantes de acordo com o tipo de prótese utilizada

\begin{tabular}{|c|c|}
\hline Tipo de próteses & $\mathrm{n}^{\circ}$ \\
\hline $\begin{array}{l}\text { PTS } \\
\text { PTI } \\
\text { PPRS } \\
\text { PPRI } \\
\text { Não faziam uso de próteses }\end{array}$ & $\begin{array}{c}149 \\
66 \\
60 \\
76 \\
145\end{array}$ \\
\hline
\end{tabular}

\subsection{Auto-percepção das condições de saúde bucal}

A auto-percepção das condições de saúde bucal é um dado importante que poderá contribuir no tratamento destes pacientes, de forma a atingir sua expectativa, em relação ao tratamento dentário.

De acordo com o Gráfico 5.2, podemos observar a avaliação das condições de saúde bucal dos participantes de suas de acordo com sua percepção. Destes, 13 consideravam suas condições de saúde bucal muito satisfatória (3,5\%), 129 consideravam satisfatória (35,0\%), 89 não consideravam nem satisfatória / nem insatisfatória (24,0\%), 117 consideravam insatisfatória $(31,0 \%)$ e 24 consideravam muito insatisfatória $(6,5 \%)$. 


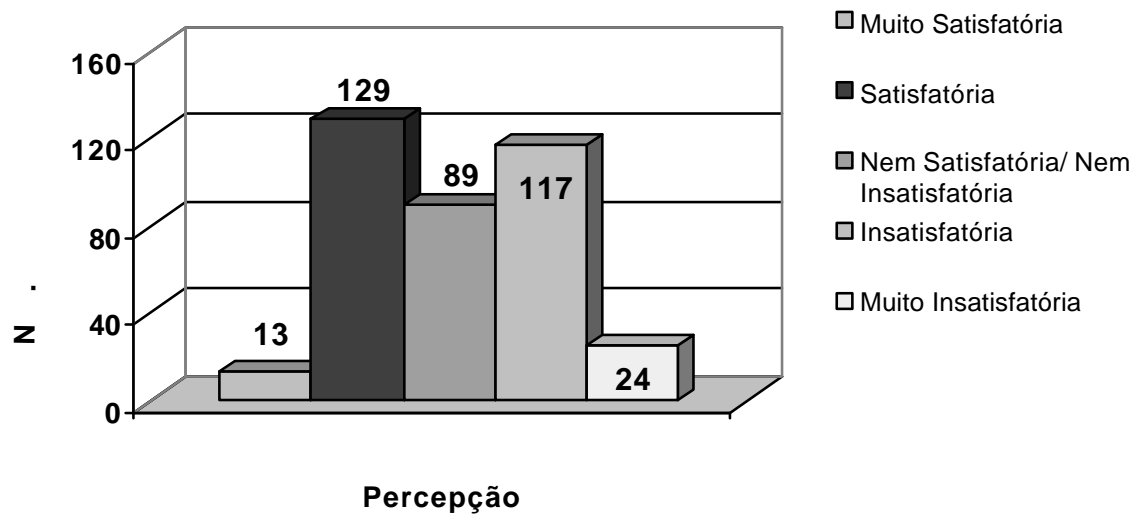

Gráfico 5.2 - Percepção das condições de saúde bucal (pelo paciente)

Nos participantes apresentando diferentes sintomas bucais, a prevalência da auto-avaliação negativa se deu com maior freqüência naqueles com dor $(61 \%)$, herpes $(60 \%)$, sangramento gengival $(56 \%)$, abscesso gengival (55\%), cárie ativa (52\%), mobilidade dental (51\%) e raiz residual $(50 \%)$, seguida de outras manifestações apresentadas na Tabela 5.11 
Tabela 5.11 - Prevalência da auto-avaliação negativa nos participantes apresentando diferentes sintomas bucais

\begin{tabular}{l|c}
\hline & Avaliação negativa (\%) \\
\hline Dor & $61 \%$ \\
Herpes & $60 \%$ \\
Sangramento gengival & $56 \%$ \\
Abcesso gengival & $55 \%$ \\
Cárie ativa & $52 \%$ \\
Mobilidade dental & $51 \%$ \\
Raiz residual & $50 \%$ \\
Queilite angular & $45 \%$ \\
Cálculo salivar & $44 \%$ \\
Extrusão dental & $44 \%$ \\
Relato de diminuição de fluxo salivar & $42 \%$ \\
Hálito cetônico & $41 \%$ \\
Gengivite & $40 \%$ \\
Grande ausência de dentes & $39 \%$ \\
Exposição radicular & $38 \%$ \\
Candidíase eritematosa & $34 \%$ \\
Hiperplasia gengival & $34 \%$ \\
Abrasão dental & $32 \%$ \\
Úlceras & $25 \%$ \\
\hline
\end{tabular}

\subsection{3 Índice de CPOD}

O número de dentes perdidos foi observado com maior freqüência na faixa etária superior aos 75 anos, onde a média foi de 26,3 elementos, conforme observado no Gráfico 5.3. Quanto ao índice CPOD encontramos 19,8 para os participantes com idade inferior a 45 anos; 21,9 na faixa etária 
entre 45 a 54 anos; 24,0 na faixa etária entre os 55 a 64 anos; 25,6 na faixa etária entre 65 a 74 anos e 29,1 acima dos 75 anos de idade.

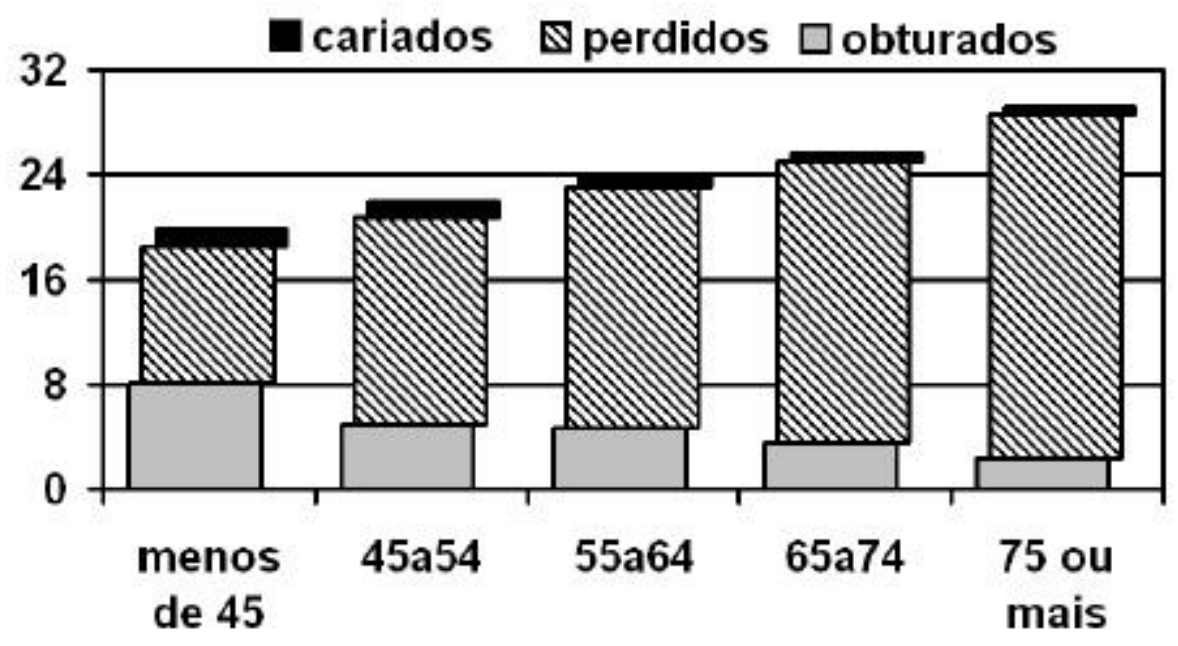

Gráfico 5.3 - Índice de CPOD dos participantes da pesquisa 


\section{DISCUSSÃO}

O DM é uma doença metabólica de elevada e crescente prevalência na população adulta, associando-se ao aumento da mortalidade por doença cardiovascular e complicações microvasculares. Muitos de seus portadores não estão em tratamento adequado e, portanto, estão expostos ao risco de desenvolver doenças e conseqüentemente risco de morte. Nesse sentido, faz-se necessário o conhecimento mais adequado de suas possíveis implicações em relação à saúde bucal. Essa interrelação vem sendo abordada por muitos autores, o que torna evidente sua importância, sendo estas implicações concordantes em tópicos relevantes, de uma forma em geral, como citada por Barcellos et al. (2000) onde relataram que os sintomas e as complicações sistêmicas irão influenciar no tratamento odontológico adequado dos pacientes e por REES (1994), que disse que a severidade e o aumento da freqüência das manifestações orais esta relacionada com a descompensação do diabetes. Por assumir características próprias em cada indivíduo, é fundamental que cada paciente portador de DM seja atendido de forma peculiar, pois as variações são derivantes desta individualidade. A constatação e definição destas características são de responsabilidade da equipe de saúde que estão 
voltadas ao atendimento dos pacientes, que dará o suporte para o tratamento odontológico, tendo como base à relação interdisciplinar. $\mathrm{O}$ profissional cirurgião dentista é responsável pela manutenção da saúde da cavidade oral, removendo focos infecciosos e restabelecendo a função mastigatória, contribuindo assim na hemostasia, devendo estar familiarizado com as manifestações sistêmicas, compreendendo o mecanismo da patologia, que terá influência no tratamento odontológico, assim como reconhecer as principais manifestações orais, tratando-as de forma efetiva e segura.

Conhecer as características desta população, suas condições clínicas sistêmicas, as condições de saúde bucal, com as manifestações bucais e sua prevalência, dará subsídios para que se possa realizar um planejamento mais seguro, diminuindo, desta forma, o número de intercorrências nas clínicas odontológicas.

Com isso discutiremos nossos achados a partir das características gerais da população estudada, direcionado, posteriormente, até as manifestações bucais.

\subsection{Distribuição por sexo e faixa etária}

Para cada faixa etária foi observada semelhança de composição por sexo, tendo no geral uma superioridade numérica de homens, encontrandose maior prevalência na faixa etária entre 55 a 64 anos (33,5\%). A literatura registra a equivalência da prevalência do DM por sexo, Shlossman et al. 
(1990), o que condiz com nossos achados; $51,5 \%$ nos homens e $48,5 \%$ nas mulheres. Quanto a faixa etária nossos resultados também são condizentes com a literatura, onde indicam que a prevalência dos portadores de DM aumenta conforme a faixa etária, sendo maiores naqueles com mais de 60 anos de idade (Ryan \& Bronstein, 1982; Sonis et al., 1996; Mattson \& Cerutis, 2001).

\subsection{Alteração glicêmica}

Quanto ao controle metabólico, encontramos um número elevado de participantes com alteração do nível de glicemia (76,5\%); hiperglicemia. Este descontrole pode estar associado a uma série de fatores, como: não acompanhamento médico, acompanhamento médico inábil, estresse, presença de infecções, erro na dieta, falta de atividade física, uso incorreto da medicação, entre outros. Barcellos et al. (2000) citaram que o descontrole metabólico parece estar relacionado ao aumento de incidência de infecções; por outro lado, a presença de infecções agrava a hiperglicemia, tornando estes pacientes susceptíveis. Cita também que devido a pouca resistência a infecção, e as péssimas condições que oferecem para uma saudável e rápida cicatrização, estes pacientes devem ser cuidadosamente preparados para intervenção cirúrgica. Para Amato Neto (1999) e Magalhães et al. (1999) durante a infecção, onde a resposta imunológica está diminuída, ocorre diminuição da quimiotaxia e da fagocitose reduzindo a imunidade celular, relacionadas aos linfócitos T e macrófagos. 
Quando da constatação da hiperglicemia este paciente deverá ser encaminhado para atendimento médico. Em relação a hipoglicemia, seu quadro já difere da hiperglicemia, pois é sintomático, com isso procedimentos poderão ser administrados pelo profissional, como solicitar que o paciente ingira líqüidos açucarados ou chás. Lauda et al. (1998) enfatizam que outras medidas devem ser tomadas se o paciente perder a consciência, como contatar o serviço de emergência e posteriormente aplicar $1 \mathrm{mg}$ de glucagon intramuscular. Alega ainda que a injeção de glucagon deve restaurar o paciente a um estado consciente em 15 minutos, quando então, deve-se dar a ele alguma forma de açúcar via oral.

Muitos profissionais acreditam que a ingestão de produtos adocicados é totalmente contra-indicado para os pacientes portador de DM. Lembramos, neste caso, que é uma conduta emergencial, devendo o paciente ser encaminhado para o serviço médico posteriormente. Acompanhar o paciente ao serviço médico é uma atitude a ser considerada, visto que nova crise durante o trajeto é passível de ocorrer.

Carboni (2001) disse também que é providencial o uso de glicosímetro, quando do atendimento, pois é um exame rápido e de bom resultado que poderá indicar quadro de hiperglicemia, que muitas vezes é assintomático.

\subsection{Fatores hereditários}

Quanto à hereditariedade, a coleta de informações na anamnese passa a ter relevância, principalmente quando não diagnosticada a 
patologia. A importância desta informação reside no fato da etiologia do DM tipo 2 basear-se na predisposição genética, como Citaram Costa \& Almeida Neto (1998). Informação esta também compartilhada por Munroe (1983); Sonis et al. (1996) e Li et al. (2001). Assunção et al. (2001) citaram, em seu estudo, a presença de familiar diabético foi mencionada por $63 \%$ dos entrevistados. Essa informação é condizente com nosso resultado, no qual $65 \%$ dos participantes relataram ter parentes genealógicos com diabetes. Destaca-se a importância deste questionamento na anamnese.

\subsection{Uso de medicações para o controle do DM}

Quanto à utilização de medicação para o controle do diabetes, este é um importante dado para a conduta do tratamento odontológico. Por vezes, o paciente é tratado com hipoglicemiantes orais ou terapia nutricional, podendo necessitar temporariamente de insulina. Dos participantes da pesquisa $62 \%$ faziam uso de hipoglicemiantes orais e $16 \%$ uso de insulina. O paciente que faz uso de insulina poderá utilizá-la em várias dosagens ao dia para sua compensação. Carboni (2001) disse que o cirurgião dentista deverá estar ciente do tipo de medicação que o paciente utilizou, seja ela insulina ou hipoglicemiante oral, assim como sua dosagem antes do procedimento odontológico, e também o tipo de ingestão alimentar e horário, pois estas condutas poderão gerar riscos ao atendimento quando não executadas corretamente, como é o caso das hipoglicemias e 
hiperglicemias, que são as ocorrências mais freqüentes nestes pacientes no consultório dentário e sendo suas características já apresentadas.

\subsection{Acompanhamento médico}

Os sinais e sintomas desta patologia, como perda de peso, poliúria, visão turva, crises de hiperglicemia, assim como as doenças associadas, fazem com que o paciente procure orientação médica, quando então é explicitada a condição de descontrole ou é realizado o diagnóstico da doença. Para o controle adequado do diabetes é essencial que seja realizado acompanhamento médico, com isso grande parte dos pacientes portadores de DM realizam este tipo de acompanhamento. Esse dado foi constatado em nosso estudo, no qual $80 \%$ estavam sob esta condição. Fraige Filho (1999) apontou que dos casos previamente conhecidos, 22,3\% não realizam qualquer tipo de tratamento ou acompanhamento médico; dado também verificado em nosso estudo.

O acompanhamento médico realizado pelos participantes da pesquisa se concentrou no SUS (61\%), enquanto $31 \%$ acessavam médicos de convênio. Esta característica pode ser justificada pelo fato dos usuários do SUS procurarem este tipo de Campanha, viabilizando exames que são muitas vezes demorados, quanto a execução e resultados. 


\subsection{Acompanhamento odontológico}

Em contrapartida, o acesso ao serviço odontológico foi menos elevado $(37 \%)$ nos participantes da pesquisa, tendo como principal característica o atendimento em consultório particular $(74,5 \%)$, seguido pelo SUS $(12,5 \%)$. Esta característica pode ser explicada pelo fato do atendimento odontológico no âmbito do SUS estar direcionado principalmente para crianças, gestantes e atendimentos emergenciais para adultos.

6.6.1 Transcrição dos depoimentos

Como observamos anteriormente, muitos pacientes que acessam os serviços não informam que são portadores de DM (24,5\%). Esta omissão pode ser prejudicial no diagnóstico, prognóstico e tratamento das afecções da cavidade bucal, além de impossibilitar o profissional de um atendimento emergencial adequado. Transcrevemos, em nossos resultados, algumas declarações dos participantes da pesquisa que omitem esta informação e as discutiremos, com o objetivo de alertar e elucidar os profissionais que os atendem:

Participante 1: "...não informo por que faço uso de dentadura em cima e embaixo..."

Comentários: Alguns participantes por não possuírem nenhum elemento dentário na cavidade bucal pressupõem que não há necessidade de visitas periódicas ao dentista, associando saúde bucal com presença e 
ausência de dente. Desconhecem que a presença das próteses totais podem ocasionar outros tipos de lesões, como úlceras, hiperplasias e candidíase e que estas lesões irão contribuir na descompensação glicêmica.

Participante 2: "...nunca me preocupei em informar o dentista..."

Participante 3 : "...não vejo relação entre o diabetes e o dentista...

Participante 4: "...não acho necessário..."

Participante 7: "... diabetes não tem nada haver com a boca..."

Participante 8: "... esqueço de dizer..."

Comentários: Estas declarações apontam para o fato de, muitas vezes, o paciente não ver o cirurgião dentista como profissional da saúde e responsável, também, pela hemostasia dos níveis de glicemia, através da eliminação dos focos de infecção bucal e manutenção da boa condição de saúde oral. Abre-se aqui uma lacuna para futuras investigações sobre este tema.

Participante 5: "...não informaria o dentista, pois teria medo de não ser tratado..."

Discussão: Esta declaração sugere que este participante já tenha sofrido algum tipo de negação de atendimento odontológico. O profissional por desconhecer o mecanismo fisiológico da doença e os cuidados no atendimento deste paciente, opta pelo encaminhamento a outro profissional. E quando este fato não é esclarecido ao paciente, este sente-se rejeitado, deixando de informar sua condição em futuras consultas.

Participante 6: "... não sabia que tinha que falar..." 
Comentários: Esta declaração se encaixa no contexto social, gerado pela falta de informação da equipe de saúde que presta atendimento a este paciente. Este tipo de consideração deveria ser colocado para reforçar a reflexão do cirurgião dentista quanto ao seu papel na sociedade.

Participante 9: "...por que o dentista nunca perguntou..."

Comentários: Aqui verificamos a falta de informação do paciente em relação à importância de sua doença e também a falha do profissional que atende este paciente quanto ao cuidado com a anamnese.

Atentamos nesta proposta de transcrição e discussão, para a falta de informação do participante quanto à importância do profissional cirurgião dentista ter conhecimento desta patologia e o quanto os problemas da cavidade bucal podem interferir na sua hemostasia.

Dos $67 \%$ que informam os profissionais de serem portadores de DM, todas as transcrições, citadas, demonstram o esclarecimento do participante quanto a importância desta informação; exceto o participante 7 que alega:

"...informo se o dentista perguntar..."

Logo, é essencial estar atento para a responsabilidade do profissional junto à coleta de informações.

Quando questionado se o dentista orientou sobre a importância da boa condição de saúde bucal no controle da glicemia, $63 \%$ dos participantes responderam negativamente, sendo um indicativo que os cirurgiões dentistas não estão buscando informações para manterem-se atualizados ou da falta de preocupação com esta orientação. 
Segundo Barcellos et al. (2000), a preocupação no atendimento odontológico do paciente portador de DM, parece estar relacionada com o desenvolvimento de distúrbios metabólicos durante as consultas e à dificuldade no controle das infecções neste tipo de paciente.

\subsection{Manifestações sistêmicas e o uso de medicação para controle}

A prevalência de manifestações sistêmicas no presente estudo foram consistentes com Cherubini et al. (2000), o quais indicaram altos índices de cardiopatia, retinopatia, nefropatia, neuropatia e hipertensão arterial nos pacientes portadores de DM tipo 2 atendidos no CAPE-FOUSP.

Quanto ao uso de medicações para o controle, observamos que dos 372 participantes, $273(73,5 \%)$ faziam uso de algum tipo de medicação. Mattson \& Cerutis (2001) relataram que algumas medicações têm repercussão bucal, como é o caso dos hipertensivos, que aumentam o potencial da xerostomia elevando, consequentemente, o risco de cárie. Quanto ao uso de alguns fármacos, Costa \& Almeida Neto (1998) alegaram que o uso de medicamentos diabetogênicos em doses altas e por tempo prolongado, como cortisona e derivados, alguns diuréticos, betabloqueadores, estrógenos, também irão favorecer o aparecimento do diabetes naqueles já predispostos. Segundo Gregori et al. (1999), na odontologia alguns fármacos de uso rotineiro podem causar queda na glicemia do paciente, como os salicilatos, a fenilbutazona (anti-inflamatório) 
e os antimicrobianos do grupo das sulfas, por este motivo, sugere o diálogo com o médico para estabelecer um plano de terapia adequado.

\subsection{Manifestações bucais}

O aumento da freqüência das manifestações bucais, segundo alguns autores, está associado à descompensação da taxa glicêmica destes pacientes (Novaes Jr. et al., 1991a; Karjalainen et al., 1994). Foi o que pudemos observar em nosso estudo, em que grande parte dos participantes apresentavam algum tipo de manifestação bucal associados a esta descompensação. A manifestação bucal que mais encontramos foi a exposição radicular com sensibilidade (58\%). Há estudos indicando que o aumento de glicose salivar ocasiona cáries cervicais, retração gengival e consequentemente sensibilidade (Bacic et al., 1989; Joshipura et al., 1991). Outro fator de risco para a exposição pode estar relacionado a idade do paciente, já que a maioria dos pacientes tipo 2 têm idade superior a 40 anos, período em que a deiscência fisiológica do tecido de sustentação leva a exposição radicular, ocasionando sensibilidade.

A gengivite foi outra manifestação bucal que ocorreu com freqüência expressiva (45\%). Essa condição, segundo Ervasti et al. (1985), pode estar relacionada ao pobre controle metabólico da doença primária associada a fatores irritantes locais, presença de placa e cálculo salivar, onde pudemos observar $42 \%$ de participantes nestas condições. Lauda et al. (1998) relataram que há alteração no epitélio gengival, com menor queratinização 
epitelial, e no tecido conjuntivo gengival e das fibras do ligamento gengival, ocasionando biossíntese retardada do colágeno com conseqüente desenvolvimento de infecção secundária, dado este também observado em nosso estudo onde $17 \%$ se apresentaram com sangramento gengival. Outro dado importante, a acrescentar ainda segundo Lauda et al. (1998), é a dificuldade do processo de reparação pós-tratamento, pois a velocidade de maturação de fibroblastos do ligamento periodontal fica retardada.

Observou-se alto índice de abrasão dental (40\%), que pode estar relacionada, segundo Conti et al. (1993), ao processo de senilidade associada aos hábitos alimentares, problemas oclusais e a grande ausência de elementos dentários nestes indivíduos, ocasionando perda de dimensão vertical de oclusão.

A proposta da Campanha, as condições de exame, assim como a falta de instrumentos mais precisos para mensuração, como sonda, e de exames complementares para diagnóstico, como radiografias, impossibilitounos avaliar a presença de doença periodontal, mesmo sabendo que esta é a patologia que mais acomete o paciente portador de DM, como citam alguns autores, com prevalência de 75\% (Sonis et al., 1996; Lauda et al., 1998; Lalla \& D'Ambrosio, 2001). Em função disto, objetivamos verificar outras manifestações que sugerissem a presença da doença periodontal como mobilidade dental, que se apresentou em $23 \%$ dos participantes e extrusão dental, com $20 \%$.

A candidíase foi observada, em sua variante eritomatosa, em $18 \%$ dos participantes, e caracterizada clinicamente como lesão avermelhada em 
região de palato duro, rebordo alveolar e dorso da língua. Achado este que relaciona esta manifestação aos portadores de DM, como citaram Guggenheimer et al. (2000), uma vez que a hiperglicemia altera a capacidade oxidativa do neutrófilo, que é responsável pelo combate ao fungo.

Apresentando-se como lesão avermelhada, em crosta ou ulcerada, em região de comissura labial, em sua maioria bilateral, a presença de queilite angular foi outra manifestação bucal encontrada nestes participantes (10\%). Para Carboni (2001) em estudo comparativo entre portadores de DM tipo 1 e tipo 2, sua prevalência é maior no primeiro grupo. Magalhães (2000) disse que a queilite pode estar associada a candidíase intrabucal e esta relacionada à imunossupressão. É importante lembrar que parte desses pacientes possuem diminuição de dimensão vertical devido à perda de grande número de dentes, criando, desta forma, um nicho para deposição do fungo, que quando associado a imunossupressão e ausência de higiene adequada pode ocasionar a queilite.

A herpes simples é uma infecção viral e também está associada a imunossupressão, sendo encontrada em $2 \%$ dos participantes e os achados basearam-se nas lesões encontradas no dia da avaliação.

O hálito cetônico clinicamente é um dado subjetivo, sendo o odor de fruta "apodrecida" um sinal clínico deste desequilíbrio glicêmico. É importante, pois pode indicar que o paciente se encontra em cetose, que pode levá-lo ao coma ou morte, devendo ser encaminhado imediatamente 
ao médico ou serviço de urgência. Em nosso estudo 15\% dos participantes se apresentaram com esta característica.

Segundo Carboni (2001), pacientes em estado de alteração hormonal, mudanças de hábitos alimentares e alteração na realização e freqüência de higiene oral associados a descompensação de suas taxas glicêmicas estão mais propensos a desenvolverem hiperplasia gengival e abcessos gengivais, dados esses observados também em outros estudos (Sonis et al., 1996; Carranza Jr., 1997). Manifestações bucais estas também observadas em nosso estudo, no qual $10 \%$ dos participantes possuíam hiperplasia gengival e $4 \%$ apresentaram-se com abscesso gengival.

Dados encontrados como: dor (22\%), exposição radicular (57\%), mobilidade dental (23\%), raiz residual (16\%), abrasão dental (40\%), úlceras (3\%) e extrusão dental (20\%) não puderam ser comparados com a literatura, visto que não encontramos trabalhos que abordassem esses temas associando com os pacientes portadores de DM.

Neville et al. (1995) disseram que a diminuição do fluxo salivar, com sintoma de ressecamento da mucosa oral, tem sido relatado como queixa em um terço dos pacientes portadores de DM. Observação esta que é constata em nosso estudo, no qual esta manifestação foi encontrada em 29\% dos participantes. Esta patologia, segundo Lamey et al. (1992) e Rees (1994), pode levar a complicações dentais que agravadas pela má higiene oral, podem causar, no paciente portador de DM, um grande desconforto. Stefaniotis \& Donta (1990) relataram em sua pesquisa com 150 pacientes tipo 2, que $76 \%$ apresentavam diminuição do fluxo salivar ou xerostomia. 
Discute que esta manifestação não tem relação com a duração da diabetes, mas sim com os valores glicêmicos do paciente. A xerostomia, caracterizada pela ausência total de saliva, Tarzia (1993), foi observada em $2 \%$ dos participantes. Segundo Zachariasen (1992), hoje se sabe que o diabetes afeta diretamente a integridade funcional e estrutural das glândulas salivares.

A diminuição do fluxo salivar, segundo alguns autores, irá comprometer a capacidade tampão da saliva, facilitando o processo de instalação da cárie (lughetti et al., 1999; Collin et al., 1998). Quanto à distribuição de cáries, foram observados índices CPO-D compatíveis com os valores de referência fornecidos pelo levantamento epidemiológico estadual de 1998 (Universidade de São Paulo, 1999): 22,4 para pessoas de 35 a 44 anos (19,8 para os participantes com DM estudados) e 28,2 para pessoas de 65 a 74 anos de idade (25,6 para os participantes com DM estudados). A análise comparativa dos componentes do índice CPO-D indicou a progressão da perda dos elementos dentários com a evolução etária. Essa observação também é compatível com os dados fornecidos pelo levantamento estadual de 1998, Universidade de São Paulo (1999), o qual apontava perda de $31,8 \%$ dos dentes de adultos de 35 a 44 anos $(32,5 \%$ para os participantes com DM estudados). e $83,2 \%$ de perda entre os idosos de 65 a 74 anos (66,9\% para os participantes com DM estudados). 


\subsection{Uso de prótese}

Em observação realizada no Centro de Atendimento a Pacientes Especiais (CAPE) da Faculdade de Odontologia da Universidade de São Paulo (FOUSP), foi constatado que grande parte dos pacientes que se apresentam ao serviço possuem perda de função mastigatória devido à ausência de elementos dentários associada às características da doença e às condições de higienização deficiente. Isto faz com que, estes pacientes, procurem o serviço com o intuito de debelar as manifestações bucais associadas à patologia e restabelecer a condição mastigatória e estética com o uso de aparelhos protéticos reabilitadores. Esta característica também foi observada no presente estudo, no qual $61 \%$ dos participantes faziam uso de próteses, sendo compatível aos percentuais de referência fornecidos pelo levantamento epidemiológico estadual de 1998 (Universidade de São Paulo, 1999): $67,5 \%$ para pessoas de 65 a 74 anos de idade (73\% para os participantes da pesquisa do mesmo grupo etário). Esta observação pode ser indicativa de necessidades de tratamento odontológico que, no grupo de pacientes com DM estudados, ainda não puderam ser contempladas. Mas este é um item importante a ser observado pelos cirurgiões dentistas que irão realizar tratamento nestes pacientes, pois muitas vezes a expectativa do tratamento se baseia em restabelecer a função e também a estética. 


\subsection{Auto-percepção das condições de saúde bucal}

Muitos pacientes procuram os cirurgiões dentistas em função da sua percepção de necessidades de tratamento. A auto-avaliação das condições de saúde bucal é um dado importante para o planejamento e instituição de medidas preventivas no serviço odontológico.

De acordo com os resultados pudemos observar que $38,5 \%$ dos participantes consideravam sua condição de saúde bucal muito satisfatória ou satisfatória, enquanto $37,5 \%$ as consideravam insatisfatória ou muito insatisfatória. Pudemos analisar que naqueles com auto-avaliação negativa, esta associação esteve relacionada com manifestações bucais com sintomatologia dolorosa, desconforto ou estética, como dor (61\%), herpes em fase aguda (60\%), sangramento gengival (56\%), abscesso gengival (55\%), cárie ativa (52\%), mobilidade dental $(51 \%)$ e raiz residual $(50 \%)$. Desta forma, é necessário que o cirurgião dentista esteja preparado para reconhecer estas manifestações, pois o tratamento apropriado contribui para a hemostasia deste paciente.

Por sua vez, os pacientes portadores de diabetes têm um papel preponderante neste controle, reconhecendo suas condições reais de saúde bucal e procurando os cuidados do cirurgião dentista para combater estas infecções. 


\subsection{Conduta odontológica}

Alguns autores alegam que cabe ao cirurgião dentista avaliar as condições gerais do paciente, verificando se ele está ou não controlado, a fim de evitar procedimentos iatrogênicos, para isso é necessário que o exame de anamnese seja minucioso, contendo informações como: tipo de diabete, duração, medicação em uso, histórico de hipoglicemia e hospitalização, reações adversas associadas com o tratamento, método de controle metabólico utilizado pelo paciente, nome do médico responsável (em caso de eventuais dúvidas da condição clínica do paciente). Posteriormente, sugere-se, avaliação médica e solicitação de exames complementares, como: glicemia em jejum, hemoglobina glicada, hemograma e coagulograma completo e teste de triglicéride e colesterol, além de um RX panorâmico da face para verificar possíveis infecções dentárias assintomáticas. Somente após estas condutas o cirurgião dentista poderá iniciar o tratamento odontológico (Justino, 1988; Sonis et al., 1996; Lauda et al., 1998; Barcellos et al., 2000).

Para Sonis et al. (1996, p. 117) a avaliação odontológica se divide em pacientes que sabem serem portadores e para aqueles que não sabe serem portadores de DM, e diz:

"O dentista deve estar atento para detectar previamente um diabete não diagnosticado, devendo a história dental incluir perguntas relativas à poliúria, polidipsia, 
polifagia e perda de peso. E os pacientes que possuem uma história positiva devem ser encaminhados a um laboratório de análise clínica, para avaliação dose-nível de glicose no sangue, ou ao seu médico, para uma avaliação adicional, antes de ser iniciado o tratamento dentário."

Justino (1988); Lauda et al. (1998) e Barcellos et al. (2000), concordaram com Sonis et al. (1996) quanto a esta distinção, e sugerem também a classificação destes pacientes em grupo de risco, sendo: baixo risco, risco moderado e alto risco, tratando-os de acordo com a gravidade das complicações, história de hipoglicemia ou cetoacidose e de acordo com os exames da taxa da glicemia em jejum e do exame de hemoglobina glicada. O autor aponta ainda para a hipoglicemia como sendo a complicação mais séria desta terapia e a necessidade do dentista conhecer seus sintomas e manifestações clínicas, as quais já foram descritas anteriormente.

Para Rees (1994), o tratamento odontológico pode ser realizado desde que o profissional esteja preparado para qualquer emergência que possa ocorrer.

No Anexo D apresentamos o protocolo de atendimento odontológico do paciente portador de diabetes utilizado no CAPE-FOUSP, com o objetivo de orientar os profissionais quanto aos cuidados demandados a estes pacientes. 
Segundo Carboni (2002, p.77), as medidas básicas no atendimento, como consultas curtas e diminuição do estresse são efetivas no transcorrer do atendimento. Citou também:

"...que o estresse associado freqüentemente às consultas odontológicas provoca descarga adrenérgica, que além de reduzir a fabricação da insulina, produz aumento de glicose liberada pelo fígado. Dessa maneira, podemos dizer que a adrenalina resultante de um estado emocional de estresse é hiperglicemiante. Por isso, é importante para o paciente diabético o condicionamento psicológico e um vínculo adequado com o cirurgião dentista para se garantir tranqüilidade durante os procedimentos."

Em vista disso, o profissional deverá, sobretudo, conhecer os mecanismos fisiopatológicos da doença, assim como as manifestações sistêmicas associadas, a ação dos fármacos, e da terapêutica medicamentosa, além das manifestações bucais associadas a doença e sua propedêutica, combatendo-as de forma a contribuir na hemostasia deste paciente. Também é necessário o conhecimento das emergências no decorrer do tratamento e como atendê-las de forma efetiva. 


\section{CONSIDERAÇÕES FINAIS}

Pacientes com DM, em sua maioria, chegam ao consultório dentário apresentando manifestações sistêmicas que interferem no atendimento odontológico, e com manifestações bucais que irão ocasionar a descompensação glicêmica. O dimensionamento das manifestações sistêmicas e bucais de pacientes diabéticos tipo 2, no momento em que se apresentaram para tratamento odontológico, indica para a equipe de saúde bucal os cuidados especiais a serem observados nesses atendimentos.

Em função das múltiplas e freqüentes manifestações bucais apresentadas por esses pacientes, os cirurgiões-dentistas devem receber informação específica para o diagnóstico e desenvolvimento desses agravos, informação esta que deverá capacitá-lo inclusive para o atendimento sob a agravante de sua condição clínica alterada.

Nesse sentido, é importante que as unidades de atendimento estejam capacitadas para a aferição dos níveis de glicemia e pressão arterial. Além disso, é necessário proceder a cuidadosa anamnese, para a caracterização das condições clínicas desses pacientes e seguir protocolos de atendimento odontológico especificamente delineados para o tratamento odontológico. 
Por outro lado ocorre desinformação dos pacientes quanto à importância do cirurgião dentista no processo de hemostasia do DM, que leva a omissão da informação da doença. Este fato poderá complicar o diagnóstico, prognóstico e tratamento das manifestações bucais e se associar a intercorrências durante o tratamento. Observa-se também que essa omissão está muitas vezes relacionada ao medo da rejeição do tratamento, sugerindo que muitos profissionais desconhecem os mecanismos e controle das emergências, sendo esse o motivo possível da recusa do cirurgião dentista no atendimento de pacientes portadores de DM. 
ANEXOS 


\section{ANEXO A}

\section{Questionário e exame das condições de saúde bucal}

№

4" Campanha Nacional Gratuita em Diabetes, de Detecção, Orientação, Educação e Prevenção das complicações - Novembro de 2001

Dados pessoais

Nome:

....Idade:

telef

Sexo: ( ) Masculino ( )

Feminino

Antecedentes familiares:

( ) $\operatorname{Sim}$

( ) Não

Em caso afirmativo:

Quem?

GLICEMIA: $\mathrm{mg} / \mathrm{dl}$

( ) Jejum

( ) Pós-prandial

Tempo que é diabético:

TIPO : ( ) 1

( ) 2 
Toma alguma Medicação:

( ) Sim ( ) Não

Em caso afirmativo: Quais?

Posologia

Acompanhamento médico :

( ) Sim ( ) Não

Em caso de SIM:

( ) Particular

( ) SUS

( ) Convênio

Acompanhamento odontológico

( ) Sim ( ) Não

Em caso de SIM:

( ) Particular

( ) SUS

( ) Convênio

Você informaria ao dentista, quando fosse realizar um tratamento odontológico, que você é portador de diabetes?

( ) $\operatorname{Sim}$ ( ) Não.

Por quê ?

Algum cirurgião dentista já lhe informou quanto a importância dos cuidados da cavidade bucal no controle da glicemia ?

( ) Sim

( ) Não

\section{Alterações metabólicas}

- ( ) Cardiopatia

( ) Nefropatia

- ( ) Retinopatia

( ) Neuropatia

- ( ) Angiopatia

( ) Hipertensão

P.A $=$ mmHg 


\section{Percepção do paciente quanto ao seu estado bucal}

( ) Muito satisfatória

( ) Satisfatória

( ) Nem satisfatória/ Nem insatisfatória

( ) Insatisfatória

( ) Muito insatisfatória

\section{Alterações orais}

- ( ) Dor

- ( ) Gengivite

- - ( ) Cálculo salivar

- ( ) Exposição radicular

- ( ) Herpes simples

- ( ) Raiz residual

- ( ) Hiperplasia gengival

- ( ) Sangramento gengival
( ) Queilite Angular

( ) Relato de diminuição do fluxo salivar

( ) Candidíase eritematosa

( ) Abcesso periodontal

( ) Mobilidade dental

( ) Hálito cetônico

( ) Abrasão dental

( ) Ulcerações

Cariados: Perdidos: ...bbturados:

OBS: Cariados: inclusive com rest.

Perdidos: inclui $3^{\circ}$ molares

Obturados: sem cárie
Higiene Oral:
( ) boa
( ) regular
( ) desfavorável

Uso de próteses:
PT:
( ) Sup
( ) $\operatorname{lnf}$
Tempo:
PPR:
( ) Sup
( ) Inf
Tempo: 


\section{ANEXO B}

\section{UNIVERSIDADE DE SÃO PAULO \\ FACULDADE DE ODONTOLOGIA}

Termo de consentimento para participação na pesquisa denominada "SUBSÍDIOS PARA O PLANEJAMENTO DE CUIDADOS ESPECIAIS PARA O ATENDIMENTO ODONTOLÓGICO DE PACIENTES PORTADORES DE DIABETES MELLITUS TIPO 2."

Paciente: №

Por este instrumento de autorização por mim assinado dou consentimento ao cirurgião-dentista Luís Antonio Cherubini Carvalho para realizar exame clínico e diagnóstico, do paciente acima qualificado.

Fui informado que este estudo tem como principal objetivo à orientação e recolher informações para adequar o tratamento odontológico aos pacientes portadores de Diabetes Mellitus, bem como a análise dos problemas bucais que o paciente diabético possa apresentar no momento que for medida sua glicemia. Concordo, pois, com toda a orientação seguida quer para fins didáticos quer para fins diagnósticos. Concordo em ser incluído neste grupo de pesquisa. 
Estou ciente que posso me recusar a participar e/ou me retirar em qualquer fase da pesquisa sem penalização alguma ou prejuízo.

Este estudo, bem como toda a metodologia que nele possa ser empregada (radiografias, fotografias, modelos, desenhos, históricos de antecedentes familiares, resultados de exames clínicos e laboratoriais e quaisquer outras informações concernentes ao planejamento, diagnóstico e tratamento) tem seu sigilo assegurado, bem como os dados confidenciais envolvidos na pesquisa.

O pesquisador/profissional afirma que o paciente não corre riscos nesta pesquisa, visto que não serão utilizadas medicações e/ou qualquer outro tipo de exame que possa comprometer o estado geral ou emocional do paciente, constando apenas de inspeção intra-oral e ficha de anamnese.

Todos os dados constituem propriedade exclusiva desta pesquisa a qual dou plenos direitos de uso para quaisquer fins de ensino e de divulgação em jornais científico do país e do estrangeiro.

São Paulo, de de 2001.

Assinatura do Paciente

(ou Responsável)
Pesquisador/profissional telef.: (11)9708-5506

RG.

$\mathrm{CIC}$ 
ANEXO C 


\section{ANEXO D}




\section{REFERÊNCIAS *}

Amato Neto VA. Diabetes e infecção. Diabetes Clin 1999; 3(4): 220-2.

Assunção MCF, Santos IS, Gigante DP. Atenção primária em diabetes no Sul do Brasil: estrutura, processo e resultado. Rev Saúde Pública 2001; 35(1): 88-100.

Bacic M, Ciglar I, Granic M, Plancak D, Sutalo J. Dental status in a group of adult diabetic patients. Community Dent Oral Epidemiol 1989; 17(6): 313-6.

Barcellos IF, Halfon VLC, Oliveira LF, Barcellos Filho I Conduta odontológica em paciente diabético. Rev Bras Odontol 2000; 57(6): 407-10.

Brasil. Ministério da Saúde. Plano de reorganização da atenção à hipertensão arterial e ao Diabetes Mellitus. Campanha nacional de detecção de suspeitos de Diabetes Melittus. Relatório técnico. Brasília: 2001.

\footnotetext{
* De acordo com Estílo Vancouver. Abreviatura de periódicos segundo Bases de Dados MEDLINE.
} 
Carboni AMG. Estudo comparativo das manifestações bucais entre os pacientes diabéticos tipo 1 e os pacientes diabéticos tipo 2. 2001.

[Dissertação de Mestrado]. Faculdade de Odontologia da USP; 2001.

Carboni AMG, Fraige Filho F. Atendimento odontológico ao paciente diabético. Diabetes Metab 1998; 2(4): 223-4.

Carranza Júnior FA. Periodontia clínica. $8^{\underline{a}}$ ed. Rio de Janeiro: Guanabara Koogan; 1997.

Cheraskin E, Ringsdorf WM, Jr. Diabetic dilemma in dentistry. Acta Diabetol Lat $1971 ; 8(2): 228-77$.

Cherubini LAC, Carboni AMG, Magalhães MHCG, Mello WR, Antunes JLF. Manifestações sistêmicas e orais em pacientes diabéticos tipo 2 atendidos no CAPE-USP. Braz Oral Res 2000; 14 Suppl 1: 25.

Childhood diabetes, epidemics, and epidemiology: an approach for controlling diabetes. World Health Organization DIAMOND Project Group on Epidemics. Am J Epidemiol 1992; 135(7): 803-16.

Collin HL, Uusitupa M, Niskanen L, Koivisto AM, Markkanen H, Meurman JH. Caries in patients with non-insulin-dependent diabetes mellitus. Oral Surg Oral Med Oral Pathol Oral Radiol Endod 1998; 85(6): 680-5. 
Consenso brasileiro sobre diabetes (CBD). Diagnóstico e classificação do diabetes mellitus e tratamento do diabetes mellitus tipo 2.

Recomendações da Sociedade Brasileira de Diabetes, 2000.

Conti PCR, Pegoraro LF, Ferreira PM, Pandolfi RF, Bonfante G.

Procedimentos para reabilitação em pacientes com desgaste dental acentuado. Rev Assoc Paul Cir Dent 1993; 47(6): 1187-91.

Costa AA, Almeida Neto JS. Manual de diabetes. $3^{\underline{a}}$ ed. São Paulo: Sarvier; 1998.

Cutler LS. Evalution and management of the diabetic dental patient. J Conn State Dent Assoc 1985; 59(2): 24-5.

Definition, diagnosis and classification of diabetes mellitus and its complications. Report of a WHO consultation. Part 1: Diagnosis and classification of diabetes mellitus. Geneva: World Health Organization, 1999. Disponível em < URL: http://whqlibdoc.who.int/hq/1999/WHO NCD NCS 99.2.pdf $>$. [2002 Nov.1]

Diabetes and periodontal diseases - position paper. J Periodontol $1996 ; .67(2): 166-76$ 
Enrich LJ, Shlossman M, Genco RJ. Periodontal disease in non-insulindependent diabetes mellitus. J Periodontol 1991; 62(2): 123-31.

Eriksson J, Forsén B, Hãggblom M, Teppo AM, Groop L. Clinical and metabolic characteristics of type 1 and type 2 diabetes: an epidemiological study from the Närpes community in Western Finland. Diabet Med 1992; 9(7): 654-60.

Ervasti T, Knuuttila M, Pohjamo L, Haukipuro K. Relation between control of diabetes and gingival bleeding. J Periodontol 1985; 56(3): 154-7.

Fraige Filho F. Dia Mundial do Diabetes. Diabetes Clin 1999: 3(4): 177.

Gaberthüel T, Curilovic Z. Der Diabetes mellitus - ein Problem für den Zahnarzt ?. Schweiz Monatsschr Zahnheilkd 1977; 87(7): 578-92.

Galili D, Fidler M, Garfunkel AA. Oral and dental complications associated with diabetes and their treatment. Compend Contin Educ Dent 1994; 15(4): 496-509.

Gregori C. Atendimento cirúrgico odontológico no paciente portador de diabetes mellitus. Ars Curandi Odontol 1974; 1(1): 29-32. 
Gregori C, Costa AA, Campos AC. O paciente com diabetes mellitus. RPG $1999 ; 6(2): 166-74$.

Gross JL, Silveiro SP, Camargo JL, Reichelt AJ, Azevedo MJ. Diabetes melito: diagnóstico, classificação, e avaliação de controle glicêmico. Arq Bras Endocrinol Metab 2002; 46(1): 16-26.

Guggenheimer J, Moore PA, Rossie K, Myers D, Mongelluzzo MB, Block HM, Weyant R, Orchard T. Insulin-dependent diabetes mellitus and oral soft tissue pathologies: II. Prevalence and characteristics of candida and candidal lesions. Oral Surg Oral Med Oral Pathol Oral Radiol Endod 2000; 89(5): 570-6.

Hother-Nielsen O, Faber O, Sorensen NS, Beck-Nielsen H. Classification of newly diagnosed diabetic patients as insulin-requiring or non-insulin-requiring based on clinical and biochemical variables. Diabetes Care 1988; 11(7): $531-7$.

Houaiss M. Diabetes mellitus, Ars Curandi Med 1987; (ed. Esp.): 12-42.

lacopino AM. Diabetic periodontitis: possible lipid-induced defect in tissue repair through alteration of macrophage phenotype and function. Oral Dis $1995 ; 1(4): 214-25$. 
lughetti L, Marino R, Bertolani MF, Bernasconi S. Oral health in children and adolescent with IDDM - a review. J Pediatr Endocrinol Metab 1999; 12 (5 Suppl 2): 603-10.

Joshipura K, Tavares M, Depapola P, Soparkar P. The prevalence of root caries in a diabetic population. J Dent Res 1991; 70(6): 979-83.

Justino DAF. Exames laboratoriais em odontologia. Rev Assoc Paul Cir Dent 1988; 42(2): 143-4.

Karjalainen KM, Knuuttiila ML, Von Dickhoff KJ. Association of severity of periodontal disease with organ complications in type 1 diabetic pacients. $\mathbf{J}$ Periodontol 1994; 65(11): 1067-72.

Kitabchi AE, Umpierrez GE, Murphy MB, Barret EJ, Kreisberg RA, Malone JL et al. Management of hyperglycemic crises in patients with diabetes, Diabetes Care 2001; 24(1): 131-53.

Lalla RV, D'Ambrosio JA. Dental management considerations for the patient with diabetes mellitus. J Am Dent Assoc 2001; 132(10): 1425-32.

Lamey PJ, Darwazeh AM, Frier BM. Oral disorders asociated with diabetes mellitus. Diabet Med 1992; 9(5): 410-6. 
Lascala NT, Moussalli NH. Periodontia clínica II. 9.e. São Paulo: Artes Medicas, 1989.

Lauda PA, Silveira BL, Guimarães MB. Manejo odontológico do paciente diabético. J Bras Odontol Clin 1998; 2(9): 81-7.

Li H, Lindholm E, Almgren P, Gustafsson A, Forsblom C, Groop L et al. Possible human leucocyte antigen-mediated genetic interaction between type 1 and type 2 diabetes. J Clin Endrocrinol Metab 2001; 86(2): 574-82.

Loe H. Periodontal disease: the sixth complication of diabetes mellitus. Diabetes Care 1993; 16(1): 329-34.

Magalhães MHCG. Estudo retrospectivo das alterações bucais em mulheres HIV positivas. [Tese de Livre-Docência]. Faculdade de Odontologia da USP; 2000.

Magalhães MHCG, Horno Neto LA, Cristante JF, Fraige Filho F, Carboni AMG. Estudo clínico das alterações bucais de pacientes diabéticos insulinodependentes - Proposta de protocolo de tratamento odontológico. Diabetes Clin 1999; 3(1): 56-60.

Mattson JS, Cerutis DR. Diabetes Mellitus: a review of the literature and dental implications. Compend Contin Educ Dent 2001; 22(9): 757-73. 
Munroe CO. The dental patient and diabetes mellitus. Dent Clin North Am 1983; 27(2): 329-40.

Nelson RG, Sholossman M, Budding MP. Periodontal disease and NIDDM in Pima Indians. Diabetes Care 1990; 13(8): 836-40.

Neville BW, Damm DD, Alien CM, Bouquot JE. Oral \& maxillofacial pathology. Philadelphia: W.B. Saunders, 1995.

Novaes Júnior AB, Pereira AL, Moraes N, Novaes AB. Manifestations of insulin-dependent diabetes mellitus in the periodontium of young Brazilian patients. J Periodontol 1991a; 62(2): 116-22.

Novaes Júnior AB, Gonzalez Gutierrez F, Grisi MF, Novaes AB. Periodontal disease progression in type II non-insulin-dependent diabetes mellitus patients (NIDDM). Part. II - Microbiological analysis using the BANA test. Braz Dent J 1991b; 8(1): 27-33.

Rocha JLL, Baggio HCC, Cunha CA, Niclewicz EA, Leite SÃO, Baptista. Aspectos relevantes da interface entre diabetes mellitus e infecção. Arq Bras Endocrinol Metab 2002; 46(3): 221-9.

Rees TD. The diabetic dental patient. Dent Clin North Am 1994; 38(3): 447-63. 
Reiner A. Oral implications of diabetes. Ann Dent 1977; 36(2): 46-54.

Ryan DE, Bronstein SL. Dentistry and the diabetic patient. Dent Clin North Am 1982; 26(1): 105-18.

Service FJ, Rizza RA, Zimmerman BR, Dyck PJ, O'Brien PC, Melton lii LJ. The classification of diabetes by clinical and C-peptide criteria. A prospective population-based study. Diabetes Care 1997; 20(2): 198-201.

Setian N, Damiani D, Dichtchekenian V. Diabetes mellitus na criança e no adolescente. São Paulo: Sarvier, 1995.

Sholossman M, Knowler WC, Pettitt DJ, Genco RJ. Type 2 diabetes mellitus and periodontal disease. J Am Dent Assoc 1990; 121(4): 532-6.

Shulkin E, Weinber J. Hospital dentistry and the diabetic. J Hosp Dent Pract 1968; 2(4): 101-5.

Solis ACO, Lotufo RFM, Lotufo Neto F. Influência do estresse sobre as doenças periodontais. RPG 2001; 8(1): 76-82.

Sonis ST, Fazio RC, Fang L. Princípios e prática de medicina oral. $2^{\underline{a}}$ ed. Rio de Janeiro: Guanabara-Koogan, 1996. 
Stefaniotis TD, Donta CN. Incidence of xerostomia in patients with drugcontrolled diabetes mellitus. Hell Stomatol Chron 1990; 34(2): 97-101.

Tarzia O. Importância do fluxo salivar com relação a saúde bucal CECADE News 1993; 1(3/4): 3-17.

Trevilatto PC, Sallum AW, Line SRP. Diagnóstico molecular da doença periodontal. Rev Assoc Paul Cir Dent 2001; 55(2): 100-3.

Ueta E, Osaki T, Yoneda K, Yamamoto T. Prevalence of diabetes mellitus in odontogenic infections and oral candidiasis: na analysis of netrophil suppression. J Oral Pathol Med 1993; 4(22): 168-74.

Universidade de São Paulo. Faculdade de Saúde Pública. Núcleo de Estudos e Pesquisas de Sistemas de Saúde. Levantamento epidemiológico em saúde bucal: Estado de São Paulo, 1998. São Paulo: FSP/USP; 1999.

World Health Organization. Oral health surveys: basic methods. $4^{\mathrm{a}} \mathrm{ed}$. Geneva: World Health Organization; 1997.

Zachariasen RD. Diabetes and xerostomia. Compend Contin Educ Dent 1992; 13(4): 314-22. 


\section{SUMMARY}

\section{SUBSIDIES FOR THE PLANNING OF SPECIAL CARES FOR ATTENDANCE DENTAL OF CARRYING PATIENTS OF DIABETES MELLITUS TYPE 2}

Beyond the systemic manifestations that occur the carrying patients of Diabetes Mellitus (DM), as angiopathies, cardiopathies, retinopathies, nephropathies and hypertension, these patients also present diminished answers the infection, when uncontrolled, making that the course of the illness if develops of differentiated form of the normoglycemic patient. This characteristic will go to present itself, also, in the buccal socket, fact this that will have to alert to the surgeon dentist how much to the adequate handling of these patients, eliminating the risks of complications during and post-cure. For in such a way, it is necessary to know the prevalence of the buccal manifestations that more occur these individuals, as well as the systemic complications associates, which will go to endanger in this behavior. The objective of this work was to present a population, already sabidamente, carrier of DM type 2, characterizing the systemic alterations and the buccal manifestations presented by these patients at the moment where if they had presented for dental attendance. We examined 372 participants, in $4^{\text {a }}$ gratuitous Campaign of prevention, education and detention in diabetes 
carried through by the National Association of Assistance to the Diabetic ANAD -. in the year of 2001, with age it enters 3287 years, being 191 of the masculine sex and 181 of the feminine sex. First was filled a questionnaire also contends auto-cited information on preexisting metabolic alterations and transcript for the fiche the value of the glycemia and arterial pressure. It was looked to verify if these participants were in medical, dental accompaniment and if they used some type of medication for control of the glycemia. The perception of conditions of buccal health also was questioned and classified in positive and negative endorsement, with scales. Later buccal examination was carried through. The results show that $46 \%$ if had presented with hypertension, the retinopathy and the nephropathy was observed in $31 \%$ of the participants, angiopathy in $20 \%$, cardiopathy in $19 \%$ and nephopathy in $10 \%$. Of participants, $80 \%$ they carried through medical accompaniment and $37 \%$ carried through dental accompaniment, being that $78 \%$ used medication for the control of the glycemia. In relation to the auto-perception of the conditions of buccal health, $38.5 \%$ evaluated positively and $37.5 \%$ evaluated negative. How much to the buccal manifestations, the findings meaningfuls had been: exposition to radicular with sensitivity (57\%), gengivitis (45\%) and reduction of flow to salivary (44\%). We conclude that in function of the multiple and frequent buccal manifestations presented by these patients, the dentist must receive specific formation for the diagnosis and development from these torts, information this that will have to also enable it to the attendance under the aggravating one of its modified clinical condition. 